\title{
Sex difference in the mouse BAT transcriptome reveals a role of progesterone
}

\author{
Kasiphak Kaikaew ${ }^{1,2, *}$, Aldo Grefhorst ${ }^{1,3, *}$, Jacobie Steenbergen ${ }^{1}$, Sigrid M A Swagemakers ${ }^{4}$, Anke McLuskey ${ }^{1}$ and \\ Jenny A Visser
}

1Department of Internal Medicine, Erasmus MC, University Medical Center Rotterdam, Rotterdam, the Netherlands 2Department of Physiology, Faculty of Medicine, Chulalongkorn University, Bangkok, Thailand

${ }^{3}$ Department of Experimental Vascular Medicine, Amsterdam University Medical Centers, Location AMC, Amsterdam, the Netherlands

${ }^{4}$ Department of Pathology and Clinical Bioinformatics, Erasmus MC, University Medical Center Rotterdam, Rotterdam, the Netherlands

Correspondence should be addressed to J A Visser: j.visser@erasmusmc.nl

*(K Kaikaew and A Grefhorst contributed equally to this work)

\begin{abstract}
Brown adipose tissue (BAT) is a metabolically active organ that exhibits sex-differential features, that is, being generally more abundant and active in females than in males. Although sex steroids, particularly estrogens, have been shown to regulate BAT thermogenic function, the underlying molecular mechanisms contributing to sexual dimorphism in basal BAT activity have not been elucidated. Therefore, we assessed the transcriptome of interscapular BAT of male and female C57BL/6J mice by RNA sequencing and identified 295 genes showing $\geq 2$-fold differential expression (adjusted $P<0.05$ ). In silico functional annotation clustering suggested an enrichment of genes encoding proteins involved in cell-cell contact, interaction, and adhesion. Ovariectomy reduced the expression of these genes in female BAT toward a male pattern whereas orchiectomy had marginal effects on the transcriptional pattern, indicating a prominent role of female gonadal hormones in this sex-differential expression pattern. Progesterone was identified as a possible upstream regulator of the sex-differentially expressed genes. Studying the direct effects of progesterone in vitro in primary adipocytes showed that progesterone significantly altered the transcription of several of the identified genes, possibly via the glucocorticoid receptor. In conclusion, this study reveals a sexually dimorphic transcription profile in murine BAT at general housing conditions and demonstrates a role for progesterone in the regulation of the interscapular BAT transcriptome.
\end{abstract}
Key Words
- brown adipose tissue
- gonadal steroid hormones
- primary cell culture
- RNA sequencing
- sex characteristics

\author{
Journal of Molecular \\ Endocrinology \\ (2021) 66, 97-113
}

\section{Introduction}

A growing number of studies suggest that the prevalence of obesity and obesity-related diseases differs between women and men. Although the global prevalence of obesity is higher in women than in men (GBD Obesity Collaborators et al. 2017), obese men are more prone to develop obesity-related conditions, such as type 2 diabetes mellitus, than obese women (Logue et al. 2011). This sex difference diminishes when women enter menopause, suggesting a prominent role for sex steroids in controlling adipose tissue function, since disturbances in adipose tissue function lead to obesity and associated metabolic diseases (Palmer \& Clegg 2015, Longo et al. 2019).

In general, two types of adipose tissue with distinct physiological functions can be recognized. 
While white adipose tissue (WAT) serves as an energy reservoir, brown adipose tissue (BAT) utilizes nutrient substrates for non-shivering thermogenesis, crucial for maintaining body temperature in small mammals and human infants (Townsend \& Tseng 2012). In BAT, thermogenesis is activated by the sympathetic nervous system (SNS) that secretes norepinephrine (NE) upon stimuli such as cold exposure. BAT thermogenesis depends on uncoupling proton transport facilitated by the mitochondrial uncoupling protein 1 (UCP1) (Cannon \& Nedergaard 2004). BAT plays a role in maintaining optimal energy balance, as illustrated by experiments in which transplantation of BAT into high-fat diet (HFD)-induced obese mice improved their body weight, fat mass, and glucose tolerance (Liu et al. 2013). However, conflicting results of the role of UCP1 in these beneficial metabolic effects exist. Feldmann et al. (2009) showed that UCP1-ablated mice housed at thermoneutral conditions become obese, whereas Maurer et al. (2020) demonstrated that UCP1ablated mice did not gain weight upon HFD feeding but did develop impaired glucose tolerance. Upon confirmation of active BAT being present in adults, BAT has been studied extensively because BAT activation is considered a potential therapeutic option for obesity and metabolic syndrome (Moonen et al. 2019).

While sex differences in WAT and the role of sex steroids herein have been addressed by numerous studies (Newell-Fugate 2017), studies on sex differences in BAT functioning and its role in sex-dependent protection against metabolic diseases is largely lacking, although some studies suggest that sex differences may exist in the presence and activity of BAT (MauvaisJarvis 2015). It was observed that the prevalence of active BAT was about two-fold higher in women than in men (Cypess et al. 2009). Also in rodents, female rats have relatively higher BAT mass and UCP1 protein levels, and larger mitochondria in BAT than males (Rodriguez-Cuenca et al. 2002). Circulating sex steroid concentrations are one of the major differences between males and females of reproductive age and therefore are obvious candidates regulating sex differences in BAT activity. Indeed, the roles of sex steroids in sexdifferential energy homeostasis have been demonstrated at many levels (Geer \& Shen 2009, Mauvais-Jarvis 2015). Especially, the effects of estrogens on systemic energy balance and BAT activity have been studied in great detail (Mauvais-Jarvis et al. 2013, Gonzalez-Garcia et al. 2017). For example, ovariectomy in rodents led to an increase in food intake, weight gain, and lipid accumulation in
WATs, as well as reduced thermogenic activity in BAT (Yoshioka et al. 1988, Rogers et al. 2009). In addition, central or peripheral injection of $17 \beta$-estradiol (E2) in ovariectomized mice induced BAT thermogenesis, demonstrating a role for estrogens in stimulating BAT activity via SNS activation (Martinez de Morentin et al. 2014). In contrast, orchiectomy induced Ucp1 mRNA expression and UCP1-positive staining in BAT coinciding with elevated body temperature, revealing an inhibitory effect of male gonadal hormones on BAT activity (Hashimoto et al. 2016). Treatment of cultured brown adipocytes with sex steroids confirmed that $\mathrm{E} 2$ facilitates while testosterone inhibits NE-induced lipolysis, an initial step of BAT thermogenesis (Monjo et al. 2003).

While sex steroids may control BAT thermogenic activity, the underlying molecular mechanisms contributing to the sex dimorphism in BAT function are still not fully elucidated. Therefore, we have performed RNA sequencing (RNA-seq) on the interscapular BAT of male and female mice to identify sex differences in the BAT transcriptome. Identified sex-differentially expressed genes were functionally clustered using biological databases. Gonadectomy (GDX) was performed to study whether sex steroids affected the expression of the identified genes. Progesterone was identified as one of the upstream regulators and we, therefore, studied the effects of progesterone on primary cultures of brown adipocytes isolated from male and female mice and on a brown adipocyte cell line.

\section{Materials and methods}

\section{Animals and housing conditions}

All animal experiments were approved by the Animal Ethics Committee at Erasmus MC, Rotterdam, the Netherlands. For the RNA-seq experiment, 8-week-old male and female C57BL/6J mice were purchased from Charles River Laboratories (Maastricht, Netherlands). Upon arrival, mice were housed at $\sim 22^{\circ} \mathrm{C}$ on a $12 \mathrm{~h}$ darkness: $12 \mathrm{~h}$ light cycle with chow diets and water available ad libitum. After 1-week acclimation, GDX or sham operation was performed as described previously (Kaikaew et al. 2017), followed by housing at standard conditions for 45 days. Next, mice were fasted for $4 \mathrm{~h}$ and euthanized by cardiac puncture under isoflurane anesthesia. BAT was snap-frozen and stored at $-80^{\circ} \mathrm{C}$ until RNA isolation.

For adipose-derived stromal vascular fraction (SVF) cell culture, male and female C57BL/6J mice were bred in the Erasmus MC animal facility and housed under the 
same conditions as described previously. At 20 weeks old, mice were euthanized and BAT was dissected and briefly stored in ice-cold PBS supplemented with AntibioticAntimycotic (Gibco, Life Technologies Europe) until SVF isolation.

\section{RNA sequencing}

Total RNA was isolated from BAT using the TriPure isolation reagent (Roche Diagnostics), contaminating genomic DNA was removed by the RQ1 RNase-free DNase (Promega Benelux), and the RNA library was prepared by the TruSeq RNA Library Prep Kit v2 (Illumina, Eindhoven, Netherlands). Paired-end sequencing with 50 base pairs in length was performed using a HiSeq 2000 sequencer (Illumina). Adapter sequences were trimmed with Cutadapt (version 1.16 with Python 3.6.4) (Martin 2011) and aligned to the mouse reference genome mm10 by RNA STAR (Galaxy version 2.6.0b-2) (Dobin et al. 2013). The number of reads was counted with featureCounts (Galaxy version 1.6.4) (Liao et al. 2014) using the genome annotation GRCm38 (release 97). The differential expression profile was analyzed in $\mathrm{R}$ with DESeq2 (version 1.25.11) (Love et al. 2014). Genes with very low expression (average counts $<3$ ) were removed and genes with the Benjamini-Hochberg (BH) adjusted $P$ value $<0.05$ were considered sex-differentially expressed. Sequencing data can be found at ArrayExpress database of the EMBL's European Bioinformatics Institute (E-MTAB-8717).

\section{Enrichment and pathway analysis}

Genes showing $\geq 2$-fold difference in sex-differential expression were uploaded in DAVID (Bioinformatics Resources, version 6.8; https://david.ncifcrf.gov/) (Huang da et al. 2009). A default functional annotation (threshold count 2 and EASE 0.1) was performed for Gene Ontology (GO). Subsequently, default functional annotation tools were selected for functional annotation clustering with a medium classification stringency (kappa similarity term overlap 3 and threshold 0.5; multiple linkage threshold 0.5 ; and EASE 0.1 ). To identify functional upstream regulators, these differentially expressed genes with their $\log _{2}$-transformed fold differences (female relative to male) were uploaded in Ingenuity Pathway Analysis (IPA, version 49309495; QIAGEN Inc., https://www.qiagenbioinformatics.com/ products/ingenuity-pathway-analysis) (Kramer et al. 2014) and analyzed using Ingenuity Knowledge Base with a default setting (direct and indirect relationships; only experimentally observed confidence).

\section{Isolation of SVF cells, cell culture, and in vitro hormonal treatment}

BAT depots from five to six mice were pooled (as a biological replicate) and BAT SVF cells were isolated and differentiated for 13 days as described previously (Grefhorst et al. 2015). However, a significant number of mice are needed to obtain enough cells for primary brown adipocyte cultures, and this limits the amount of experimental conditions that we could test in primary differentiated adipocytes. To reduce the number of mice, we, therefore, decided to use T37i cells, the female murine brown adipocyte cell line (a gift provided by Dr M. Lombès, Inserm U1185, France) (Zennaro et al. 1998), for progesterone stimulations. T37i cells were maintained and differentiated for 9 days as described previously (Kaikaew et al. 2019).

Fully differentiated BAT SVF or T37i cells were steroid-starved for $3 \mathrm{~h}$ in the starvation medium (medium containing $\quad 0.2 \%$ dextran-coated charcoal-treated fetal bovine serum (DCC-FBS), prepared as previously described (Kaikaew et al. 2019)), followed by pretreatment with 5 or $500 \mathrm{nM}$ of RU486 (Sigma-Aldrich) or EtOH vehicle for $60 \mathrm{~min}$. Subsequently, cells were stimulated with progesterone (Steraloids, Newport, RI, USA) or EtOH vehicle for $24 \mathrm{~h}$ by adding the indicated concentrations to the RU486- or EtOH-pretreated cultured media.

To study the effect of progesterone on T37i cell differentiation, cells were treated with the indicated concentrations of progesterone or $\mathrm{EtOH}$ vehicle supplemented to steroid-deprived differentiation medium (similar to the normal T37i differentiation medium, except replacing 10\% FBS with 9\% DCC-FBS and 1\% FBS). For NE stimulation of differentiated T37i cells, cells were starved for $3 \mathrm{~h}$ in $0.2 \%$ DCC-FCS starvation medium and subsequently stimulated for $24 \mathrm{~h}$ with $1 \mu \mathrm{M}$ NE (SigmaAldrich) or $\mathrm{HCl}$ vehicle.

\section{Adiponectin and glycerol measurement}

Cultured media of progesterone and/or RU486-treated SVF-differentiated brown adipocytes and NE-stimulated T37i cells were collected, centrifuged for $10 \mathrm{~min}$ to remove debris, and stored at $-20^{\circ} \mathrm{C}$ until measurement. Adiponectin concentrations were determined using the mouse HMW \& total adiponectin ELISA kit (Alpco Diagnostics, Salem, NH, USA) and glycerol concentrations 
were determined using the glycerol reagent set (INstruchemie, Delfzijl, Netherlands), according to the manufacturers' protocols.

\section{Quantitative PCR}

Reverse transcription and quantitative PCR (qPCR) were performed using the Transcriptor high-fidelity cDNA synthesis kit and the FastStart Universal SYBR Green Master (Rox) (both from Roche Diagnostics) with a QuantStudio 7 flex real-time PCR system (Applied Biosystems, Life Technologies). Samples that yielded too little RNA were not included in the qPCR analysis. Gene expression was normalized to the indicated housekeeping genes using the $2^{-\Delta \Delta C T}$ method. Primer sequences are listed in Table 1.

\section{Statistical analysis}

Data were analyzed in GraphPad Prism (GraphPad Software, Inc.). Differences in gene expression levels, considered at $P<0.05$, were analyzed with one-way or two-way ANOVA with appropriate post hoc tests, indicated in each figure legend. Unless otherwise indicated, data are presented as mean \pm S.E.M.

Table 1 Primer sequences.

\begin{tabular}{|c|c|c|}
\hline Gene & Forward $\left(5^{\prime} \rightarrow 3^{\prime}\right)$ & Reverse $\left(5^{\prime} \rightarrow 3^{\prime}\right)$ \\
\hline Adipoq & GCACTGGCAAGTTCTACTGCAA & GTAGGTGAAGAGAACGGCCTTGT \\
\hline $\operatorname{Ar}$ & TCCAAGACCTATCGAGGAGCG & GTGGGCTTGAGGAGAACCAT \\
\hline Bax & TGAAGACAGGGGCCTTTTTG & AATTCGCCGGAGACACTCG \\
\hline$B c / 2$ & GGACTTGAAGTGCCATTGGT & CATCACGATCTCCCGGTTAT \\
\hline$B m p 8 b$ & CAACCACGCCACTATGCAG & CACTCAGCTCAGTAGGCACA \\
\hline$C 7$ & CAACTGCAAGTGGGACTCCTA & CAGCAACTGAACGCCTTCG \\
\hline Cdh1 & AGACTTTGGTGTGGGTCAGG & ATCTGTGGCGATGATGAGAG \\
\hline Cfd & CTACAAGCGATGGTATGATGTGC & GGACCCAACGAGGCATTCT \\
\hline Cldn3 & AGTGCTTTTCCTGTTGGCGGCTCT & ATCGCGGCGCAGAATAGAGGATCT \\
\hline Cldn4 & CAGTGCAAGATGTACGACTCGAT & TACCACTGAGAGAAGCATCCCC \\
\hline Cldn7 & AGGGTCTGCTCTGGTCCT & GTACGCAGCTTTGCTTTCA \\
\hline $\mathrm{Cxcl13}$ & CATAGATCGGATTCAAGTTACGCC & TCTTGGTCCAGATCACAACTTCA \\
\hline Epcam & GCGGCTCAGAGAGACTGTG & CCAAGCATTTAGACGCCAGTTT \\
\hline Esr1 & TGGGTCATGAGAGTCCTTTGAA & CCGGGATGGAAACTGAACTTT \\
\hline Fabp4 & GCGAGTAGAATGACAGCTCCTT & CTGTCGTCTGCGGTGATTT \\
\hline Fkbp5 & ATTTGATTGCCGAGATGTG & TCTTCACCAGGGCTTTGTC \\
\hline $\operatorname{Irf4}$ & TGCAAGCTCTTTGACACACA & CAAAGCACAGAGTCACCTGG \\
\hline Krt5 & TCTGCCATCACCCCATCTGT & CCTCCGCCAGAACTGTAGGA \\
\hline Krt8 & CAAGGTGGAACTAGAGTCCCG & CTCGTACTGGGCACGAACTTC \\
\hline Krt14 & ССАССТTТСАТСТTСССАATТСТC & GTGCGGATCTGGCGGTTG \\
\hline Krt18 & CTGGAGGATGGAGAAGATTT & CTTTTATTGGTCCCTCAGTT \\
\hline $\operatorname{Len} 2$ & ACTTCCGGAGCGATCAGTT & CAGCTCCTTGGTTCTTCCAT \\
\hline Lep & ACCCCATTCTGAGTTTGTCC & TCCAGGTCATTGGCTATCTG \\
\hline Mupa & CAAAACAGAAAAGGCTGGTGA & TTGTGCAAACCTTTCCTTGA \\
\hline Nr3c1 & CCGGGTCCCCAGGTAAAGA & TGTCCGGTAAAATAAGAGGCTTG \\
\hline $\mathrm{Nr3c2}$ & GAAGAGCCCCTCTGTTTGCAG & TCCTTGAGTGATGGGACTGTG \\
\hline Pgr & GGGGTGGAGGTCGTACAAG & GCGAGTAGAATGACAGCTCCTT \\
\hline Pparg & GAAAGACAACGGACAAATCACC & GGGGGTGATATGTTTGAACTTG \\
\hline Ppargc1a & CCCTGCCATTGTTAAGACC & TGCTGCTGTTCCTGTTTTC \\
\hline Ptprf & TGCTCTCGTGATGCTTGGTTT & ATCCACGTAATTCGAGGCTTG \\
\hline Scnn1b & ACCCGGTGGTTCTCAATTTGT & AAGTTCCGCAAGGTACACACA \\
\hline Sdc1 & TGGAGAACAAGACTTCACCTTTG & CTCCCAGCACTTCCTTCCT \\
\hline St14 & TCATCGCCTACTACTGGTCAGAGT & TGGCGCGATCAACCTCTT \\
\hline $\operatorname{Tsc} 22 d 3$ & CAGCAGCCACTCAAACCAGC & ACСАСАТССССТССАAGCAG \\
\hline Ucp1 & GGCCTCTACGACTCAGTCCA & TAAGCCGGCTGAGATCTTGT \\
\hline Wfdc2 & AACCAATTACGGACTGTGTGTT & TCGCTCGGTCCATTAGGCT \\
\hline$A c t b^{*}$ & AAGGCCAACCGTGAAAAGAT & GTGGTACGACCAGAGGCATAC \\
\hline$B 2 m *$ & ATCCAAATGCTGAAGAACGG & CAGTCTCAGTGGGGGTGAAT \\
\hline Hprt* & GCAGTACAGCCCCAAAATGG & AACAAAGTCTGGCCTGTATCCAA \\
\hline Rn18s* & GTAACCCGTTGAACCCCATT & CCATCCAATCGGTAGTAGCG \\
\hline
\end{tabular}

aThe primers detect multiple genes of the MUP family due to its high similarity in mRNA sequences. *Housekeeping genes. 


\section{Results}

\section{BAT transcriptional profile of male and female mice}

RNA-seq analysis identified 17,798 transcripts in the interscapular BAT of mice. Expression levels of these identified transcripts are visualized by the relative female-to-male fold differences in Fig. 1A. A total of 2,038 genes were identified being sex-differentially expressed (unadjusted $P<0.05$ ), but when accounting for a $\mathrm{BH}$ correction at $P<0.05$ only 596 transcripts remained, of which 347 genes (58.2\%) showed a female-biased expression and 249 genes (41.8\%) showed a male-biased expression (Fig. 1A and B). Further trimming by applying a cut-off of two-fold difference resulted in 295 significantly sex-differentially expressed genes, of which 242 genes (82.0\%) showed higher expression and 53 genes (18.0\%) showed lower expression in female BAT than in male BAT (Fig. 1B). Hierarchical clustering analysis of the 295 genes illustrates the differences in the transcriptional profile of BAT between male and female mice (Fig. 1C).

\section{Analysis of biological processes of the sex-differentially expressed genes}

Of the 295 sex-differentially expressed genes, 291 genes were matched in the DAVID mouse data resources.
Top GO annotation terms from enrichment analyses are presented in Table 2 and top significant functional annotation clusters are presented in Table 3 . In general, among the leading significant categories and clusters are genes that encode proteins involved in cellular structure and cell-cell contact, interaction, and adhesion.

\section{Validation of the sex-differentially expressed genes by qPCR and influences of GDX}

We selected a subset of genes with a high sex-differential expression level, corresponding to the first five significant functional annotation clusters. The summary of their known biological function is reported in Supplementary Table 1 (see section supplementary materials given at the end of the article). Since sex steroids have been implicated to contribute to sex differences in BAT function (Gonzalez-Garcia et al. 2017), expression of these selected genes was validated in BAT of both sham-operated and gonadectomized mice by qPCR (Fig. 2). This analysis confirmed that sham-operated female mice had higher BAT mRNA expression of cell adhesion and structural molecules, for example, epithelial cadherin (E-cadherin), claudins, epithelial cell adhesion molecule (EpCAM),
A

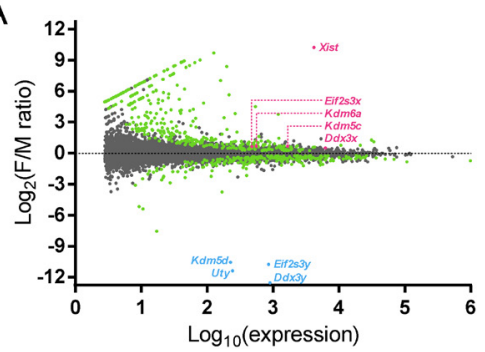

B

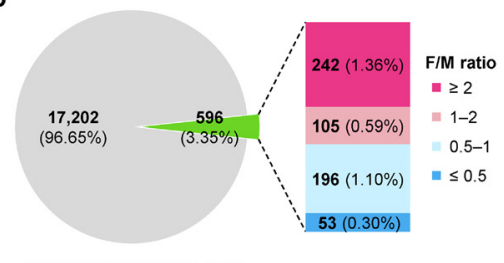

Total 17,798 identified genes

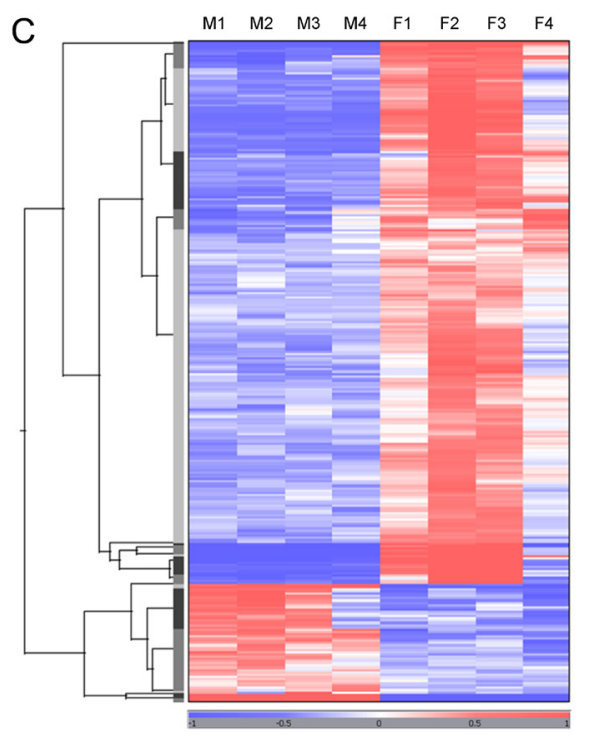

Figure 1

Sex difference in BAT RNA-seq profile. (A) Scatter plot demonstrating expression levels of all identified genes. Log-transformed average normalized counts of genes in BAT are presented on the $X$ axis and log-transformed fold changes are presented on the $Y$ axis, with positive values indicating female-biased expression and negative values indicating male-biased expression. Blue and pink dots represent known differentially expressed genes and serve as internal controls: blue indicates $\mathrm{Y}$-chromosomal genes, whereas pink indicates $X$ gametologs of the $Y$-chromosomal genes and the major $X$ inactivation gene, Xist. Green dots indicate the significant sex-differentially expressed genes (BH-adjusted $P<0.05$ ). (B) Pie and bar chart demonstrating the number and percentage of identified genes. A two-fold cut-off was applied to select genes with a substantial sex-dependent expression. (C) Heat map and dendrogram presenting the expression of the 295 sexdifferentially expressed genes (BH-adjusted $P<0.05$ and differential expression $\geq 2$ folds) in BAT of four male (M1-M4) and four female (F1-F4) mice. The heat map was visualized with the TreeScape (OmniViz, version 6.1.13.0). Red indicates upregulation and blue indicates downregulation, compared to the geometric mean of the rlog-normalized expression levels of each gene, and the color intensity represents the magnitude of the difference. 
Table 2 Top GO terms in each annotation category by enrichment analysis in DAVID.

\begin{tabular}{|c|c|c|c|}
\hline GO term & Count & $\%$ & $P$ value \\
\hline \multicolumn{4}{|l|}{ Biological process } \\
\hline Cell adhesion & 23 & 7.90 & $7.00 \mathrm{E}-7$ \\
\hline Mammary gland alveolus development & 5 & 1.72 & $1.05 \mathrm{E}-4$ \\
\hline Cellular response to platelet-derived growth factor stimulus & 5 & 1.72 & $2.30 \mathrm{E}-4$ \\
\hline Sodium ion transport & 9 & 3.09 & $2.73 E-4$ \\
\hline Positive regulation of fat cell differentiation & 6 & 2.06 & $4.95 E-4$ \\
\hline Canonical Wnt signaling pathway & 7 & 2.41 & 0.001 \\
\hline \multicolumn{4}{|l|}{ Cellular component } \\
\hline Extracellular exosome & 87 & 29.90 & $2.89 \mathrm{E}-16$ \\
\hline Extracellular region & 60 & 20.62 & $8.36 \mathrm{E}-12$ \\
\hline Proteinaceous extracellular matrix & 23 & 7.90 & $2.02 \mathrm{E}-10$ \\
\hline Extracellular space & 48 & 16.49 & $1.79 \mathrm{E}-8$ \\
\hline Apicolateral plasma membrane & 7 & 2.41 & $2.17 \mathrm{E}-7$ \\
\hline Cell junction & 29 & 9.97 & $2.68 \mathrm{E}-7$ \\
\hline \multicolumn{4}{|l|}{ Molecular function } \\
\hline Structural molecule activity & 16 & 5.50 & $5.19 \mathrm{E}-7$ \\
\hline Symporter activity & 10 & 3.44 & $1.63 \mathrm{E}-5$ \\
\hline Cell adhesion molecule binding & 8 & 2.75 & $3.88 \mathrm{E}-5$ \\
\hline Protein binding & 78 & 26.80 & $2.43 \mathrm{E}-4$ \\
\hline Scaffold protein binding & 6 & 2.06 & $6.28 \mathrm{E}-4$ \\
\hline $\begin{array}{l}\text { Transcriptional activator activity, RNA polymerase II core promoter } \\
\text { proximal region sequence-specific binding }\end{array}$ & 12 & 4.12 & $8.79 \mathrm{E}-4$ \\
\hline
\end{tabular}

Count indicates the number of sex-differentially regulated genes in the GO term and \% was calculated based on the total of 291 sex-differentially expressed genes uploaded in DAVID. $P$ value indicates a modified Fisher exact test, the DAVID enrichment (EASE score) analysis.

keratins, and syndecan-1 than sham-operated male mice (Fig. 2). Ovariectomy significantly reduced the expression of this selected subset of genes, but orchiectomy only had marginal effects. Hence, female gonadal factors are likely important regulators of the expression of cell adhesion and structural molecules in interscapular BAT of mice.

\section{Analysis of possible upstream regulators and its regulated genes}

Upstream regulator analysis in IPA was used to identify possible regulators of the sex-differentially expressed genes. Top significant upstream regulators are presented in Table 4 . In the gene, RNA, and protein category, erb-b2 receptor tyrosine kinase 2 (ERBB2, also known as human EGF receptor 2 (HER2)) and transforming growth factor beta-1 (TGF 1 1) were identified as the top upstream regulators. The predicted state for ERBB2 on sex-differential (female-over-male) BAT transcriptome was an activation $(Z=3.58)$. This was also predicted for TGF $\beta 1$ albeit with lower confidence $(Z=1.48)$. Interestingly, another top identified upstream regulator was the estrogen receptor which is in line with E2 being the top upstream regulator in the endogenous chemical category (Table 4). The activation state for E2 on sex-differential (female-overmale) BAT transcriptome was predicted as an activation $(Z=3.88)$. Another female sex steroid, progesterone, was predicted as the second upstream regulator in the endogenous chemical category and its activation state was possibly an activation $(Z=1.35)$. Dihydrotestosterone (DHT) was also identified as an upstream regulator, but its activation state was uncertain $(Z<1)$.

The identification of E2 and estrogen receptor as upstream regulators is in line with previous studies implicating a role for $\mathrm{E} 2$ in the activation of BAT (Gonzalez-Garcia et al. 2017). However, the involvement of progesterone in BAT function is less clear. Therefore, we further investigated the effects of progesterone on BAT.

\section{Effects of progesterone on sex-differentially expressed genes in SVF-differentiated brown adipocytes}

Direct effects of progesterone on the transcription of the validated sex-differentially expressed genes reported in Fig. 2 were assessed in SVF-differentiated primary brown adipocytes. Ingenuity identified a total of 25 genes as progesterone-regulated molecules in our dataset, of which 9 genes (Cdh1, Cfd, Cldn3, Cldn4, Krt5, Lcn2, Pgr, $S c n n 1 b$, and $W f d c 2)$ were among the qPCR-validated genes in BAT. We first determined whether these 9 IPAidentified progesterone-regulated genes were detectable in SVF-differentiated brown adipocytes by qPCR. We could only detect mRNA expression of $C f d, L c n 2$, and Pgr in 
Table 3 Top functional annotation clusters by DAVID, presenting only GO terms.

\begin{tabular}{|c|c|}
\hline Cluster 1 & nrichment score 10.351 \\
\hline GO terms & xtracellular region; extracellular space \\
\hline Genes & $\begin{array}{l}\text { Acta2, Actg2, Adamts15, Adamts18, Alcam, Ano9, Anxa2, Apln, Aqp5, Areg, Atp4b, Bglap3, Bmp8b, Bnc2, Bsn, } \\
\text { Btn1a1, C7, Ccdc3, Ccr3, Cdcp1, Cdh1, Cdh3, Cdh11, Cel, Cfd, Chil1, Clca3a2, Col4a6, Col9a2, Col12a1, Col17a1, } \\
\text { Csn3, Ctse, Cxcl13, Cxcl15, Dkkl1, Dmbt1, Dmkn, Dsg2, Epcam, Ephb3, Ezr, Faim2, Fam20c, Fbn2, Fcgbp, Fetub, } \\
\text { Fgb, Flrt1, Frem1, Fxyd3, Galnt3, Gcnt4, Ggt1, Gldn, Glt1d1, Gpr156, Gpx3, Hc, Igfals, Il17b, Itgb3, Itih2, Krt8, Krt14, } \\
\text { Krt18, Krtdap, Lad1, Lama1, Lamc2, Large2, Lcn2, Lgals7, Ltf, Lvrn, Ly6d, Mfap2, Mfap4, Mfsd2a, Muc15, Mup1a, } \\
\text { Myc, Ncan, Nectin4, Nipal2, Npr3, Nt5e, Olfm2, Oxtr, Pdgfd, Phyhip, Piezo2, Plb1, Plet1, Plod2, Plppr3, Prlr, Proc, } \\
\text { Prom1, Prom2, Prtn3, Ptk7, Ptn, Ptprf, Ptprn2, R3hdml, S100a9, Scg3, Scnn1b, Sdc1, Serpinb5, Slc1a1, Slc5a1, } \\
\text { Slc5a5, Slc5a7, Slc5a8, Slc5a9, Slc6a13, Slc12a2, Slc38a1, Slc44a4, Slco2a1, Slit2, Spint2, Spon1, St14, Sucnr1, } \\
\text { Tacstd2, Thsd4, Tlr5, Tmem119, Tmprss2, Tmprss13, Tpbg, Tspan1, Upk3a, Vtcn1, Wfdc2, Wfdc18, Wisp2, Wnt7b }\end{array}$ \\
\hline luster 2 & Enrichment score 3.902 \\
\hline & embrane \\
\hline Gel & $\begin{array}{l}\text { Abcc8, Alcam, Ano9, Anxa2, Ap1m2, Aqp5, Areg, Atp4b, Atp6v1b1, Basp1, Bnc2, Btn1a1, Cacna1g, Cadps2, Ccr3, } \\
\text { Cdcp1, Cdh1, Cdh3, Cdh11, Cldn3, Cldn4, Cldn7, Cldn8, Clic6, Col17a1, Ddx3y, Dmbt1, Dsg2, Dsp, Epcam, Ephb3, } \\
\text { Esyt3, Ezr, Faim2, Fer1l4, Fermt1, Flrt1, Fxyd3, Galnt3, Gcnt4, Ggt1, Gldn, Gpr156, Hpd, Irf4, Irs1, Itgb3, Kcng4, Krt5, } \\
\text { Krt19, Lamc2, Large2, Lvrn, Ly6d, Marveld3, Mfsd2a, Mmd2, Mrgprg, Mtmr7, Muc15, Ncan, Nectin4, Nipal2, Npr3, } \\
\text { Nt5e, Olfm2, Oxtr, Pdgfd, Perp, Pgr, Piezo2, Pkp1, Plb1, Plch2, Plet1, Plod2, Plppr3, Pmepa1, Prlr, Prom1, Prom2, } \\
\text { Prtn3, Ptk7, Ptn, Ptprf, Ptprn2, S100a14, S100a9, Scg3, Scnn1b, Sdc1, Slc1a1, Slc5a1, Slc5a5, Slc5a7, Slc5a8, Slc5a9, } \\
\text { Slc6a13, Slc12a2, Slc35f3, Slc38a1, Slc44a4, Slco2a1, Slit2, Smim3, Spint2, St14, Sucnr1, Syt14, Tacstd2, TIr5, } \\
\text { Tmem45b, Tmem56, Tmem119, Tmprss2, Tmprss13, Tpbg, Tspan1, Tusc5, Upk3a, Vtcn1, Wisp2, Wnt7b, Wwc1, } \\
\text { 6430571L13Rik }\end{array}$ \\
\hline luste & Enric \\
\hline rms & vity. \\
\hline Genes & $\begin{array}{l}\text { Actg2, Cacna1g, Cdh1, Cgn, Cldn3, Cldn4, Cldn7, Cldn8, Col4a6, Dsp, Ezr, Fgb, Krt5, Krt8, Krt14, Krt15, Krt17, Krt18, } \\
\text { Krt19, Lad1, Sprr1a }\end{array}$ \\
\hline Iuster 4 & Enric \\
\hline GO terms & \\
\hline Genes & $\begin{array}{l}\text { Atp4b, Cacna1g, Clic6, Fxyd3, Kcng4, Lcn2, Ltf, Mfsd2a, Mup1a, Piezo2, Scnn1b, Slc1a1, Slc5a1, Slc5a5, Slc5a7, } \\
\text { 8, Slc5a9, Slc6a13, Slc12a2, Slc38a1, Slco2a1 }\end{array}$ \\
\hline Iuster 5 & nt score 3.022 \\
\hline GO terms & $\begin{array}{l}\text { Apicolateral plasma membrane; bicellular tight junction; calcium-independent cell-cell adhesion via plasma } \\
\text { membrane cell-adhesion molecules }\end{array}$ \\
\hline Genes & $\begin{array}{l}\text {, Cdh1, Cdh3, Cgn, Cldn3, Cldn4, Cldn7, Cldn8, Epcam, Ezr, Krt8, Krt19, Mapk13, Marveld3, Perp, Pof1b, Ptprf, } \\
\text { rf1, Sdc1, Vtcn1 }\end{array}$ \\
\hline
\end{tabular}

aMup1 was entered in DAVID as a representative for Mup22 due to its highly similar protein sequences (https://www.uniprot.org/uniprot/Q4FZE8).

differentiated SVFs, of which levels at basal conditions confirmed the higher expression levels in female than in male BAT, although only Cfd and Pgr expression reached statistical significance (Fig. 3A). Progesterone stimulation for $24 \mathrm{~h}$ revealed that progesterone dose-dependently reduced $C f d$ mRNA expression in differentiated SVFs of both sexes (Fig. 3B), while it induced Lcn2 (Fig. 3C) but reduced $P g r$ (Fig. 3D) mRNA expression more prominently in female adipocytes than in male adipocytes.

Apart from $P g r$, which encodes the nuclear progesterone receptor (PR) and is a known progesterone-regulated gene, we also investigated the mRNA expression of other nuclear receptors to determine whether they may underlie the progesterone effects. Interestingly, progesterone dosedependently reduced $N r 3 c 1$ (encoding the glucocorticoid receptor (GR)) mRNA expression in adipocytes of both sexes (Fig. 3E), but progesterone did not significantly affect mRNA expression of the mineralocorticoid receptor and the androgen receptor (data not shown). Moreover,
mRNA expression of a GR-target gene Tsc22d3 (also known as glucocorticoid-induced leucine zipper (Gilz)) was dosedependently upregulated by progesterone treatment of differentiated SVFs (Fig. 3F), implicating the involvement of GR signaling in the progesterone effects in these SVFs.

As RU486 is a PR- and GR-antagonist with a more PR-specific competitive antagonism at low concentrations (i.e. $5 \mathrm{nM}$ ) and a dual PR- and GR-antagonism at high concentrations (i.e. $500 \mathrm{nM}$ ) (Kroon et al. 2018), we co-administered progesterone with 5 or 500 nM RU486 to study the contribution of PR and GR in the observed progesterone effects. Noticeably, the progesterone-induced upregulation of $T s c 22 d 3$ mRNA expression remained unaffected upon $5 \mathrm{nM}$ RU486 co-administration but was blocked in the presence of 500 nM RU486 (Fig. 3F), confirming the specificity of the selected RU486 doses. Similarly, we observed that progesterone-regulated $C f d$, $L c n 2$, and $P g r$ mRNA expression levels were marginally affected by 5 nM RU486, but were completely blunted 


\begin{tabular}{|c|c|c|c|c|c|c|}
\hline \multirow{2}{*}{ Genes } & \multirow{2}{*}{$\begin{array}{c}\text { RNA-seq F/M ratio, } \\
\text { mean }(95 \% \mathrm{Cl})\end{array}$} & \multicolumn{5}{|c|}{ qPCR relative expression level, mean $\pm S E M$} \\
\hline & & Male sham & Female sham & Male GDX & Female GDX & Sig. \\
\hline Epcam & $520.3(88.4-3060.7)$ & $1.00 \pm 0.37$ & $698.2 \pm 247.9^{\$}$ & $0.27 \pm 0.07$ & $19.00 \pm 11.01$ \$.\# & $\times, S, G$ \\
\hline $\mathrm{Pgr}^{\dagger}$ & $439.9(43.7-4433.0)$ & $1.00 \pm 0.49$ & $1.80 \pm 0.38$ & $0.42 \pm 0.25$ & $0.15 \pm 0.08 \#$ & G \\
\hline$W f d c 2^{\dagger}$ & $343.6(69.3-1703.1)$ & $1.00 \pm 0.18$ & $155.8 \pm 15.9^{\$}$ & $0.96 \pm 0.08$ & $6.91 \pm 2.03$ s.\# & $\times, S, G$ \\
\hline Krt8 & $332.5(68.3-1619.0)$ & $1.00 \pm 0.22$ & $2616.0 \pm 588.2^{\$}$ & $0.94 \pm 0.12$ & $63.07 \pm 46.06^{\$ \text { \$ } \#}$ & $\times, S, G$ \\
\hline Cldn $4^{\dagger}$ & $315.0(49.8-1992.2)$ & $1.00 \pm 0.07$ & $1486.6 \pm 387.7^{\$}$ & $1.22 \pm 0.10$ & $56.81 \pm 7.47 \$$ & $\times, S, G$ \\
\hline Krt14 & $243.6(45.4-1308.0)$ & $1.00 \pm 0.41$ & $172.8 \pm 48.8^{5}$ & $0.39 \pm 0.06$ & $5.55 \pm 3.08(\$), \#$ & $\times, S, G$ \\
\hline$K r t 5^{\dagger}$ & $197.8(38.5-1014.7)$ & $1.00 \pm 0.19$ & $6.35 \pm 1.26^{\$}$ & $1.04 \pm 0.26$ & $1.26 \pm 0.33 \#$ & $\times, S, G$ \\
\hline Krt18 & $129.5(37.0-453.2)$ & $1.00 \pm 0.28$ & $788.6 \pm 143.9^{\$}$ & $0.34 \pm 0.08$ (\#) & $20.91 \pm 7.82$ s.\# & $\times, S, G$ \\
\hline Mup22 & $38.31(7.08-207.4)$ & $1.00 \pm 0.20$ & $17.17 \pm 6.73^{\$}$ & $0.92 \pm 0.29$ & $1.46 \pm 0.65 \#$ & $\times, S, G$ \\
\hline Scnn $1 b^{\dagger}$ & $25.90(4.44-151.2)$ & $1.00 \pm 0.19$ & $34.53 \pm 12.61^{\$}$ & $0.60 \pm 0.08$ & $1.99 \pm 0.42 \#$ & $S, G$ \\
\hline Cldn3' & $19.18(7.50-49.06)$ & $1.00 \pm 0.21$ & $103.6 \pm 33.1^{\$}$ & $1.59 \pm 0.49$ & $6.26 \pm 1.29$ s.\# & $\times, S, G$ \\
\hline$B m p 8 b$ & $18.80(9.08-38.92)$ & $1.00 \pm 0.57$ & $28.46 \pm 12.26^{\$}$ & $0.29 \pm 0.06$ & $1.71 \pm 0.19$ s.: & $(x), S, G$ \\
\hline Cdh1 ${ }^{\dagger}$ & $17.19(7.98-37.02)$ & $1.00 \pm 0.04$ & $26.86 \pm 7.88^{\$}$ & $0.69 \pm 0.23$ & $2.12 \pm 0.45^{\text {s.\# }}$ & $\times, S, G$ \\
\hline $\operatorname{Lcn}^{+}$ & $10.33(5.75-18.56)$ & $1.00 \pm 0.62$ & $4.98 \pm 2.14^{\$}$ & $0.77 \pm 0.39$ & $0.32 \pm 0.13 \#$ & $(\times),(G)$ \\
\hline St14 & $8.20(3.88-17.35)$ & $1.00 \pm 0.28$ & $11.90 \pm 3.05^{\$}$ & $0.67 \pm 0.19$ & $2.84 \pm 0.65$ s.\# & $S, G$ \\
\hline Cldn7 & $7.33(2.69-19.97)$ & $1.00 \pm 0.18$ & $25.20 \pm 6.40^{\mathrm{s}}$ & $0.60 \pm 0.11$ & $2.95 \pm 0.84$ s.\# & $\times, S, G$ \\
\hline Irf4 & $3.08(2.15-4.41)$ & $1.00 \pm 0.29$ & $3.23 \pm 0.41^{\$}$ & $2.34 \pm 0.56^{(\#)}$ & $1.11 \pm 0.30 \#$ & $x$ \\
\hline Ptprf & $2.53(1.63-3.94)$ & $1.00 \pm 0.15$ & $1.97 \pm 0.50$ & $0.79 \pm 0.12$ & $0.64 \pm 0.06 \#$ & G \\
\hline $\mathrm{Cfd}^{\dagger}$ & $2.41(1.74-3.33)$ & $1.00 \pm 0.30$ & $5.17 \pm 1.02^{\$}$ & $1.78 \pm 0.25$ & $1.05 \pm 0.33 \#$ & $\times,(S)$ \\
\hline Sdc1 & $2.36(1.70-3.26)$ & $1.00 \pm 0.11$ & $1.77 \pm 0.31^{\$}$ & $0.96 \pm 0.09$ & $0.75 \pm 0.14 \#$ & $\times, G$ \\
\hline Cxcl13 & $0.14(0.08-0.25)$ & $1.00 \pm 0.29$ & $0.39 \pm 0.09$ & $2.95 \pm 1.32$ & $0.22 \pm 0.10^{\$}$ & $(x), S$ \\
\hline C7 & $0.07(0.06-0.10)$ & $1.00 \pm 0.31$ & $0.08 \pm 0.00^{\$}$ & $1.12 \pm 0.46$ & $0.12 \pm 0.03 \$$ & S \\
\hline
\end{tabular}

Figure 2

Validation of gene expression by qPCR and influences of sex and GDX on sex-differential expression in BAT. The relative female/male (F/M) expression ratios by RNA-seq (4 mice per group) are shown in descending order in the left column. DESeq2-estimated $\log _{2}$-transformed fold changes (Ifc) and the standard error of the Ifc (IfCSE) were used to calculate the F/M ratio by $2^{\text {lfc }}$ and the $95 \%$ $\mathrm{Cl}$ by $2^{\mathrm{Ifc}-1.96(\mathrm{ffCSE})}$ and $2^{\mathrm{ffc}^{\mathrm{f}}+1.96(\mathrm{ffCSE})}+\dagger$ indicates genes that the Ingenuity database identified as progesterone-regulated molecules. The other columns present relative expression levels measured by qPCR (four to six mice per group). Expression levels were normalized to $B 2 m$ and Rn18s and are shown relative to the shamoperated male mice. The Sig. column lists significant effects $(P<0.05)$ analyzed from the log-transformed expression levels by two-way ANOVA: G for gonadal status (sham or GDX), $\mathrm{S}$ for sex, and $\times$ for an interaction between $\mathrm{G}$ and $\mathrm{S}$. $\$$ indicates a significant sex difference between mice with the same gonadal status and \#indicates a significant effect of gonadal status within the same sex, by post hoc test $(P<0.05)$. Symbol in parentheses indicates a tendency to significance $(P<0.10)$. Color demonstrates $\log _{2}$-transformed relative expression levels. GDX, gonadectomy. with $500 \mathrm{nM}$ of RU486 cotreatment (Fig. 3B, C and D), suggesting GR-mediated responses of progesterone on these genes.

Next, we determined whether progesterone could affect the expression of the 13 qPCR-validated sexdifferentially expressed genes not present in the IPA database of progesterone-regulated molecules (Fig. 2). By qPCR, only the mRNA expression of C7, Ptprf, Scd1, and Krt14 was detectable in SVF-differentiated adipocytes (Fig. 3G). Unlike the expression pattern observed in interscapular BAT, we found that mRNA expression levels of $C 7$ were higher in female than in male SVFdifferentiated adipocytes and progesterone treatment stimulated C7 mRNA expression in differentiated adipocytes of both sexes (Fig. $3 \mathrm{H}$ ). This stimulatory effect was abolished by $500 \mathrm{nM}$ but marginally affected by $5 \mathrm{nM}$

Table 4 Upstream regulator analysis of sex-differential expression in BAT by IPA.

\begin{tabular}{l}
\hline Upstream regulator \\
\hline Genes, RNAs, and proteins \\
ERBB2 \\
Estrogen receptor \\
TGFB1 \\
CAV1 \\
KLF4 \\
CEBPA \\
TNF \\
CCN5 \\
SOX2 \\
EGF \\
Endogenous chemicals \\
$17 \beta$-estradiol \\
Progesterone \\
Tretinoin \\
Dihydrotestosterone
\end{tabular}

\begin{tabular}{l} 
Molecule type \\
\hline Kinase \\
Group \\
Growth factor \\
Transmembrane receptor \\
Transcription regulator \\
Transcription regulator \\
Cytokine \\
Growth factor \\
Transcription regulator \\
Growth factor \\
\\
Endogenous chemical \\
Endogenous chemical \\
Endogenous chemical \\
Endogenous chemical
\end{tabular}

\begin{tabular}{c}
\hline Activation $\boldsymbol{Z}$ score \\
\hline \\
3.58 \\
1.43 \\
1.48 \\
- \\
3.55 \\
0.22 \\
1.15 \\
1.27 \\
0.58 \\
1.23 \\
3.88 \\
1.35 \\
-0.10 \\
0.53 \\
\hline
\end{tabular}

$P$ value of overlap

$1.16 \mathrm{E}-15$

2.43E-15

7.14E-13

$1.53 \mathrm{E}-12$

$1.51 \mathrm{E}-11$

$5.91 \mathrm{E}-11$

$4.68 \mathrm{E}-10$

$6.00 \mathrm{E}-10$

9.36E-10

1.07E-09

2.45E-11

$1.78 \mathrm{E}-7$

$3.02 \mathrm{E}-7$

$6.20 \mathrm{E}-5$

Activation $Z$ score identifies upstream regulators that can explain observed gene expression fold changes in the dataset and predicts the activation state of the possible upstream regulators based on the Ingenuity Knowledge Base. $Z>2$ indicates a significant prediction of an activated state whereas $Z<-2$ indicates a significant prediction of an inhibited state. $P$ value of overlap indicates enrichment of the database-known regulated genes in the dataset. 
A

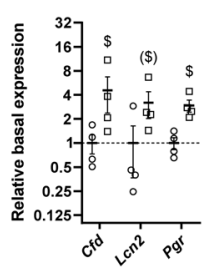

B

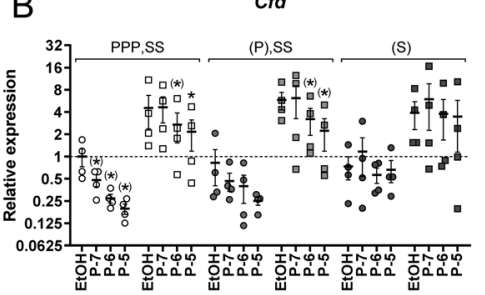

E

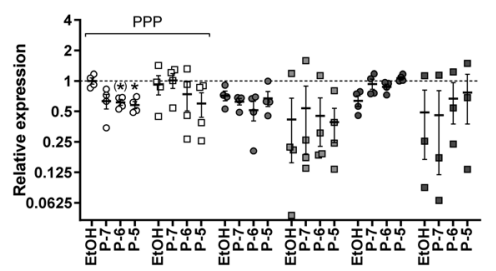

C

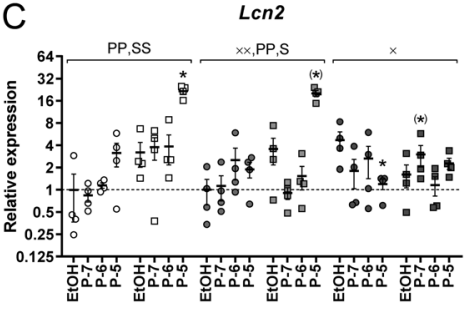

$\mathrm{F}$

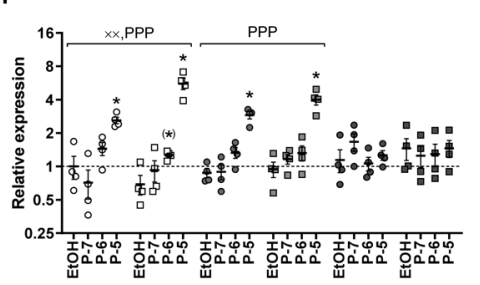

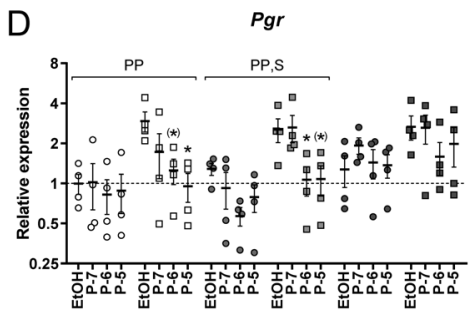

- male, $\mathrm{EtOH}$

- female, EtOH

- male, RU $5 \mathrm{nM}$

- female, RU $5 \mathrm{nM}$

- male, RU $500 \mathrm{nM}$

- female, RU $500 \mathrm{nM}$

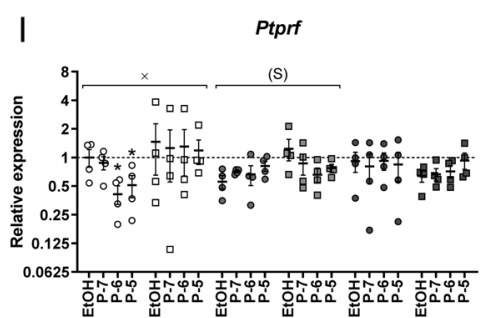

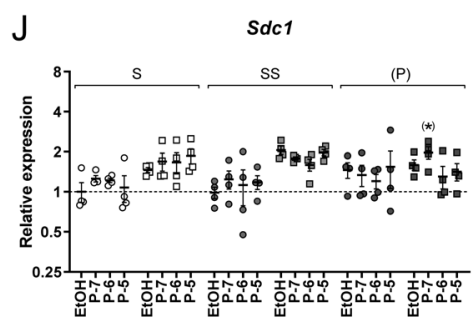

\section{Figure 3}

Effects of progesterone on the RNA-seq-identified sex-differentially expressed genes in SVF-differentiated brown adipocytes. SVF-derived primary cultures of brown adipocytes from male and female BAT were stimulated with progesterone at indicated concentrations: P-7 (10-7 M), P-6 (10-6 M), or P-5 (10-5 M), together with RU486 (5 or $500 \mathrm{nM}$ ) or EtOH vehicle. Expression levels were normalized to Actb and Hprt, depicted relative to the level of EtOH-treated male adipocytes, and presented as mean \pm S.E.M. (four biological replicates per condition). Data were log-transformed before statistical analyses. Basal mRNA expression levels of (A) the RNA-seq-identified sex-differentially expressed and IPA-identified progesterone-regulated genes and $(\mathrm{G})$ the remaining RNA-seq-identified sex-differentially expressed genes. \$indicates a significant sex difference $(P<0.05)$ or $(\$)$ indicates a tendency to differ $(P<0.10)$ by unpaired $t$ tests. $(B, C, D, E, F$ and $\mathrm{H}, \mathrm{I}, \mathrm{J}) \mathrm{mRNA}$ expression levels of the indicated genes. Two-way repeated measures ANOVA was performed to identify the effects of sex and progesterone in each RU486 condition. Significant effects are presented as follows: (S), $P_{\text {sex }}<0.10 ; \mathrm{S}, P_{\text {sex }}<0.05 ; \mathrm{SS}, P_{\text {sex }}<0.01 ;(\mathrm{P}), P_{\text {progesterone }}<0.10 ; \mathrm{PP}, P_{\text {progesterone }}<0.01 ; \mathrm{PPP}, P_{\text {progesterone }}<0.001 ; \times, P_{\text {sexxprogesterone }}<0.05$; and $\times x$, $P_{\text {sexxprogesterone }}<0.01$. Dunnett's post hoc tests were applied when appropriate. * indicates a significant difference $(P<0.05)$ and $(*)$ indicates a tendency to differ $(P<0.10)$ from the EtOH control.

RU486 cotreatment. Progesterone marginally inhibited PtprfmRNA expression only in male-derived differentiated adipocytes (Fig. 3I) but did not affect $S d c 1$ (Fig. 3J) and Krt14 (data not shown) mRNA expression in cells of either sex. Of note, the finding that mRNA expression of only 7 out of 22 qPCR-validated sex-differentially expressed genes in interscapular BAT were detectable in primary brown adipocytes (Fig. 3A and G) may suggest that these other 15 genes are expressed by other cell types in the BAT depot.

\section{Effects of progesterone on adipocyte markers in SVF-differentiated brown adipocytes}

Since our results suggest that progesterone may regulate some of the sex-differentially expressed genes in BAT, we next determined whether progesterone affects adipocyte function by analyzing the expression of common adipocyte markers in differentiated SVFs. At basal conditions, mRNA expression of Ucp1 and its transcription activator Ppargc1a appeared to be higher in female than in male SVFs differentiated into adipocytes, but both failed to reach significance $(P>0.10$; Fig. 4A). Female differentiated SVFs had higher expression levels of adipogenic differentiation and maturation genes Pparg, Fabp4, and Adipoq than male differentiated SVFs (Fig. $4 A)$. In addition, female differentiated SVFs had a lower expression of the classical white adipocyte marker Lep than male differentiated SVFs, suggesting a more metabolically active phenotype of female differentiated brown adipocytes (Fig. 4A), although it should be noted that Lep mRNA expression was relatively low in these cells $\left(C_{T}\right.$ values of samples were only $\sim 1.36 \pm 0.01$ lower than negative controls). Progesterone treatment did not significantly affect expression levels of Ucp1 (Fig. 4B), Ppargc1a (Fig. 4C), Pparg 
A

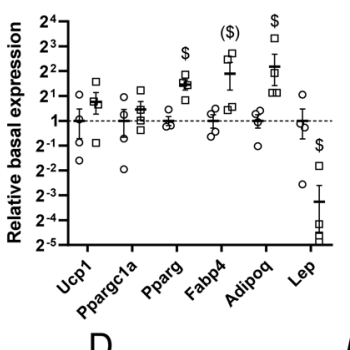

D

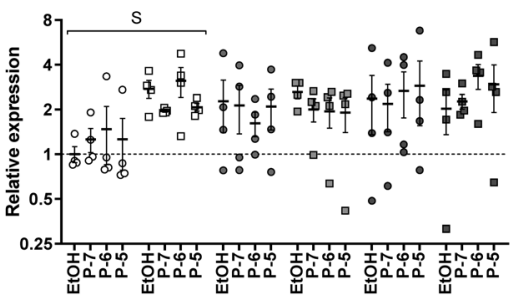

F

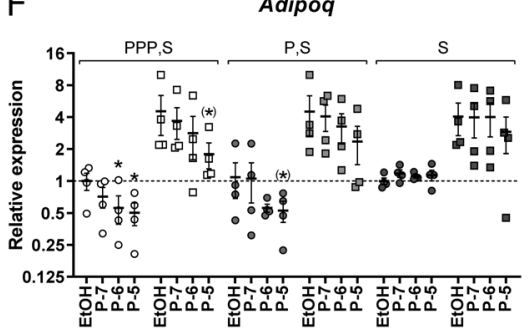

B

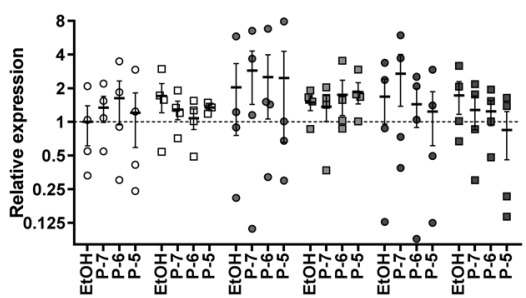

C

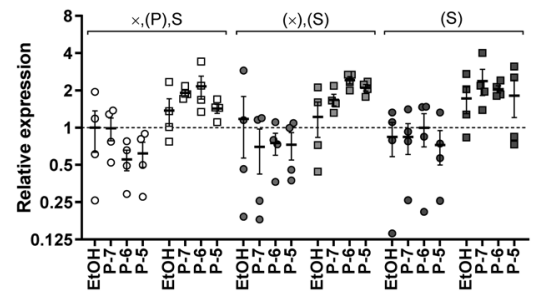

E

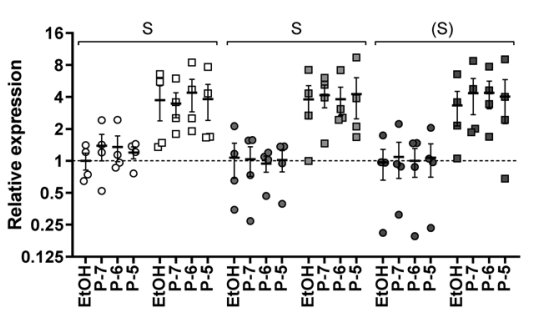

- male, EtOH

- female, EtOH

- male, RU $5 \mathrm{nM}$

- female, RU $5 \mathrm{nM}$

- male, RU $500 \mathrm{nM}$

- female, RU $500 \mathrm{nM}$

G Adiponectin in cultured media

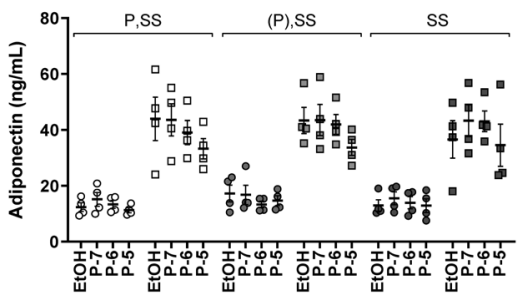

Figure 4

Effects of progesterone on adipocyte markers in SVF-differentiated brown adipocytes. SVF-derived primary cultures of brown adipocytes from male and

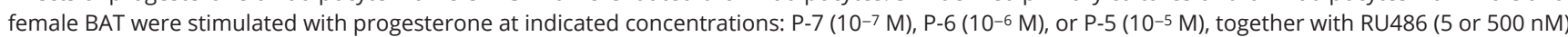
or EtOH vehicle. Data are presented as mean \pm S.E.M. (four biological replicates per condition). (A) Basal mRNA expression levels of common adipocyte markers. \$indicates a significant sex difference $(P<0.05)$ or $(\$)$ indicates a tendency to differ $(P<0.10)$ by unpaired $t$ tests. $(B, C, D, E$ and F) mRNA expression levels of the indicated genes. mRNA expression levels were normalized to Actb and Hprt, depicted relative to the level of EtOH-treated male adipocytes, and log-transformed before statistical analyses. (G) Adiponectin (protein) concentrations in cultured media of the cells with progesterone/ RU486 stimulation. Two-way repeated measures ANOVA was performed to identify the effects of sex and progesterone in each RU486 condition. Significant effects are presented as follows: (S), $P_{\text {sex }}<0.10 ; \mathrm{S}, P_{\text {sex }}<0.05 ; \mathrm{SS}, P_{\text {sex }}<0.01 ;(\mathrm{P}), P_{\text {progesterone }}<0.10 ; \mathrm{P}, P_{\text {progesterone }}<0.05 ; \mathrm{PPP}, P_{\text {progesterone }}<0.001$; $(\times), P_{\text {sexxprogesterone }}<0.10$; and $\times, P_{\text {sexxprogesterone }}<0.05$. Dunnett's post hoc tests were applied when appropriate. ${ }^{*}$ indicates a significant difference $(P<0.05)$ and $\left(^{*}\right)$ indicates a tendency to differ $(P<0.10)$ from the EtOH control.

(Fig. 4D), and Fabp4 (Fig. 4E). Intriguingly, progesterone dose-dependently reduced Adipoq mRNA expression in differentiated SVFs of both sexes (Fig. 4F), of which the inhibitory effect of progesterone was also likely driven by GR since the effect was marginally affected by $5 \mathrm{nM}$ RU486 but was blunted by $500 \mathrm{nM}$ RU486 co-treatment. In addition, these results of Adipoq mRNA expression were confirmed at the protein level, through measurement of adiponectin levels in cultured media of the SVF-differentiated brown adipocytes (Fig. 4G).

\section{Effects of progesterone in a brown adipocyte cell line}

Next, we analyzed the effects of progesterone on adipocyte differentiation. To limit the number of mice, we first analyzed whether the effects of progesterone on the expression of common brown adipocyte markers were also present in T37i, a female brown adipocyte cell line (Zennaro et al. 1998). Differentiated T37i were stimulated with progesterone for $24 \mathrm{~h}$. High-dose progesterone significantly reduced $U c p 1$ mRNA expression (Fig. 5A) but did not significantly affect Ppargc1a mRNA expression (Fig. 5B). In contrast, Pparg mRNA expression was induced by high doses of progesterone (Fig. 5C). Interestingly, Fabp 4 mRNA expression was induced by $10^{-6}$ and $10^{-5.5} \mathrm{M}$ progesterone but reduced by $10^{-5} \mathrm{M}$ progesterone (Fig. 5D). Expression levels of both adipokines Adipoq and Lep were reduced by high-dose progesterone stimulation (Fig. 5E and F).

Concerning the expression of receptors that can potentially mediate progesterone effects, we found that Pgr mRNA expression was not detectable in T37i cells 

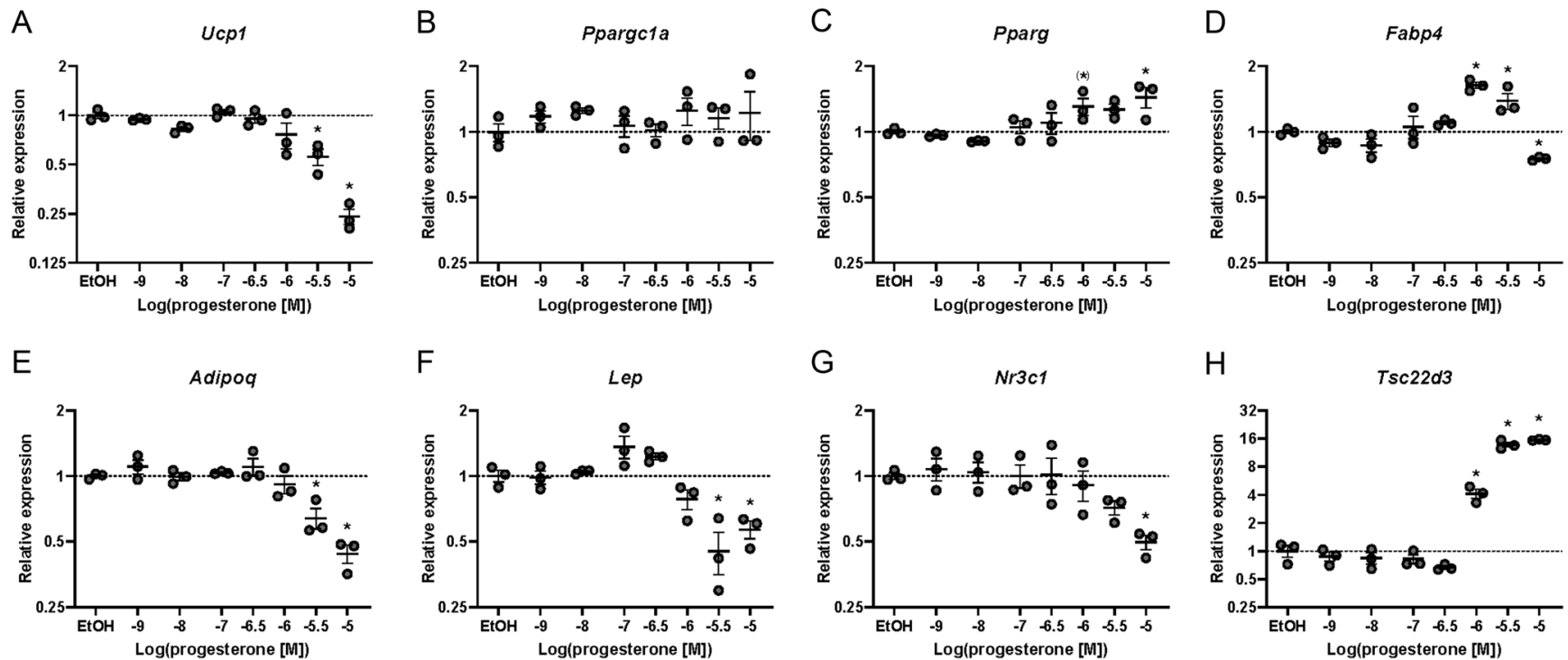

Figure 5

Effect of progesterone on differentiated T37i brown adipocytes. Differentiated T37i brown adipocytes were treated for $24 \mathrm{~h}$ with progesterone at indicated concentrations. Expression levels were normalized to $A c t b$ and $B 2 m$, depicted relative to the EtOH vehicle-treated condition, and presented as mean \pm S.E.M. (three biological replicates per condition). Data were log-transformed before statistical analyses with one-way ANOVA. *indicates a significant difference $(P<0.05)$ and $(*)$ indicates a tendency to differ from the EtOH-treated condition $(P<0.10)$ by Dunnett's post hoc tests.

(data not shown) while Nr3c1 mRNA expression was downregulated by progesterone (Fig. 5G). Transcription levels of the GR-target genes Tsc22d3 (Fig. 5H) and Fkbp5 (data not shown) were dose-dependently upregulated.

Since progesterone affected the expression of Pparg (the master transcriptional activator of adipogenesis) and Ucp1 in differentiated T37i cells, we next determined the impact of progesterone on T37i differentiation by adding progesterone to the differentiation cocktail. Ucp1 and Ppargc1a (the transcriptional activator of mitochondrial biogenesis) mRNA expression levels were strongly upregulated during differentiation $\left(P_{\text {day }}<0.001\right)$ but were significantly inhibited in the presence of highdose progesterone (Fig. 6A and B). In contrast, Pparg mRNA expression was induced by co-stimulation with $10^{-6} \mathrm{M}$ progesterone (Fig. 6C), while expression of the mature adipocyte marker Fabp4 in the mature adipocytes (day 9) was not significantly affected by progesterone (Fig. 6D). However, at the early differentiation phase (day 3), $10^{-7} \mathrm{M}$ and $10^{-6} \mathrm{M}$ progesterone-induced Adipoq mRNA expression, but this effect was absent at later stages when even a downregulation was seen at $10^{-5} \mathrm{M}$ progesterone after 9 days of differentiation (Fig. 6E). Lep mRNA expression was inhibited at the highest dose of progesterone treatment throughout differentiation (Fig. 6F). Of note, mRNA expression levels of a pro-apoptotic marker Bax and an anti-apoptotic marker $\mathrm{Bcl} 2$ were not significantly affected by progesterone co-treatment (data not shown), suggesting that progesterone did not hamper cell survival. Subsequently, we tested the NE-induced thermogenic activity in differentiated T37i cells with/ without progesterone treatment during differentiation. Co-treatment with high-dose progesterone during differentiation significantly inhibited baseline mRNA expression levels of Ucp1 (Fig. 6G) and Ppargc1a (Fig. 6H). However, progesterone-treated cells remained responsive to NE since NE stimulation induced the expression of these thermogenic genes in T37i cells, although NE-induced expression levels were reduced in cells treated with high-dose progesterone (Fig. 6G and H). Furthermore, NE-induced glycerol release from T37i cells (a proxy for thermogenic activity) was dose-dependently reduced by progesterone treatment during adipocyte differentiation (Fig. 6I).

\section{Discussion}

To the best of our knowledge, this is the first study to investigate sex differences in the global transcriptional profile by RNA-seq in the interscapular BAT of mice at reproductive age and at basal housing conditions at $\sim 22^{\circ} \mathrm{C}$. Functional annotation and clustering showed enrichment of genes encoding proteins involved in cellular structure, cell-cell contact, and cell adhesion. Although female BAT 
A

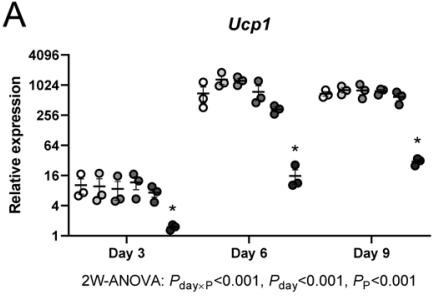

D

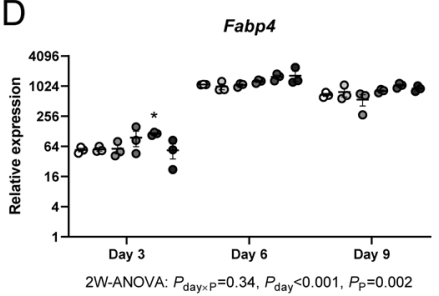

G

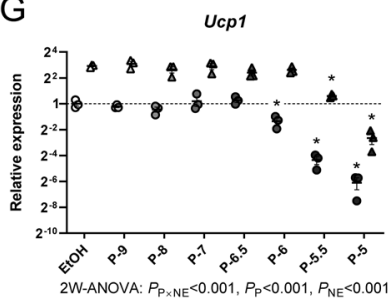

B

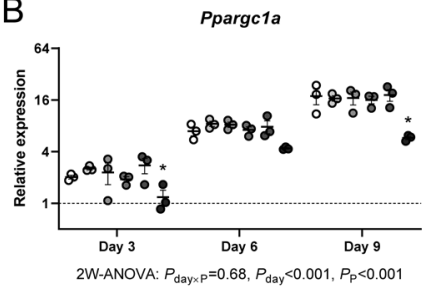

E

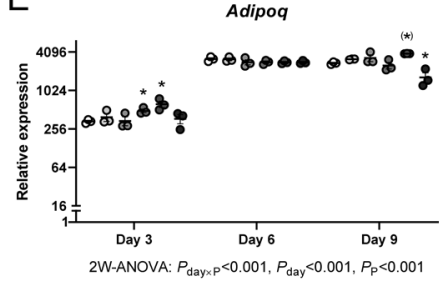

$\mathrm{H}$

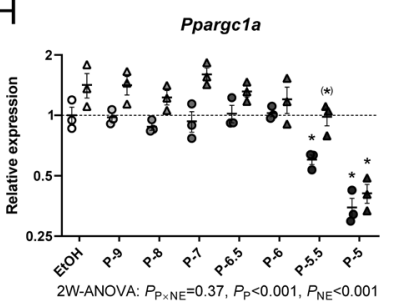

C

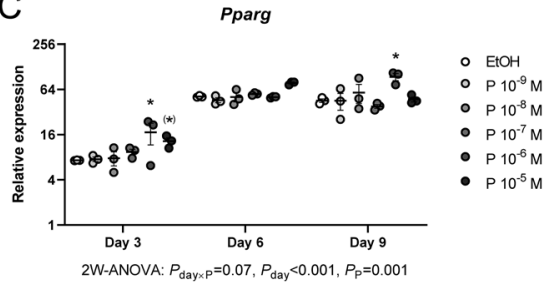

F
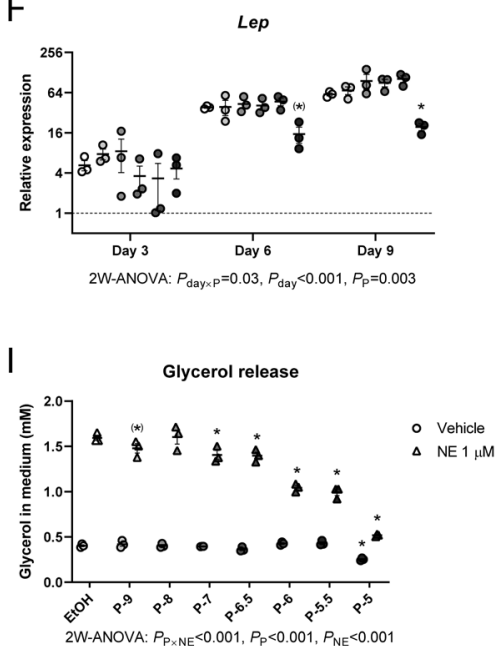

Figure 6

Effect of progesterone treatment during differentiation of T37i brown adipocytes. Progesterone (P) at indicated concentrations were treated during differentiation of T37i brown preadipocytes until full differentiation at day 9. Data are presented as mean \pm S.E.M. (three biological replicates per condition). Gene expression data were log-transformed before statistical analyses with two-way ANOVA. *indicates a significant difference $(P<0.05)$ and $(*)$ indicates a tendency to differ $(P<0.10)$ from the EtOH-treated condition by Dunnett's post hoc tests. $(A, B, C, D, E$ and F) Days after differentiation, when the differentiating cells were collected, are plotted on the $\mathrm{X}$ axis. Expression levels were normalized with $A c t b$ and $B 2 m$ and depicted relative to the levels in undifferentiated cells (day 0). (G, H and I) Nine-day differentiated cells with/without progesterone during differentiation were stimulated for 24 h with $1 \mu \mathrm{M}$ of norepinephrine (NE) or vehicle and analyzed for mRNA expression or glycerol release in cultured media. Gene expression levels were normalized with $A c t b$ and $B 2 m$ and depicted relative to levels of the EtOH-treated/vehicle-stimulated condition. Concentrations of progesterone treatment during differentiation are indicated on the X axis as follows: P-9 (10-9 M), P-8 (10-8 M), P-7 (10-7 M), P-6.5 (10-6.5 M), P-6 (10-6 M), P-5.5 (10-5.5 M), and P-5 (10-5 M).

was isolated randomly throughout the estrous cycle, the sex-differential expression remained apparent suggesting a robust sex-dependent regulation of transcription in BAT. In support, we confirmed our previous findings by this approach, showing that Bmp8b is sex-differentially expressed in BAT (Grefhorst et al. 2015).

Cell adhesion is an essential process in maintaining tissue structure and cellular interaction with neighboring cells or with the extracellular matrix (ECM) (Gumbiner 1996). Structural and adhesion proteins, such as E-cadherin, claudins, and keratins, are well-known for their role in this process as well as in epithelial-tomesenchymal transition, cancer progression, and tumor metastasis (Basu et al. 2018). Keratins were identified exclusively in omental WAT, but not in subcutaneous WAT, and have been suggested to play a role in the development of the inflammation process, but also to contribute to mechanical stress of adipocytes during obesity (PerezPerez et al. 2009). However, the role of structural and adhesion proteins in BAT is less clear, although the microenvironment is shown to be important for visceral and subcutaneous WAT morphology and function, including the formation of new vessels to promote optimal tissue expansion (Choe et al. 2016, Pope et al. 2016). Upon HFD feeding of mice, male gonadal WAT showed a lack of angiogenesis whereas female gonadal WAT had a high vascular density, together with an upregulation of the angiogenic factors, for example, Vegfa and Vegfr2 (Rudnicki et al. 2018). In support of our findings in BAT, a study comparing obesity-prone and obesity-resistant rats upon HFD feeding showed that genes encoding proteins involved in cell structure and motility constituted almost a quarter of the differentially expressed genes, with the lowest expression in the obesity-prone rats (Joo \& Yun 2011). However, no major overlap was observed between the genes detected in that study with our identified genes. Importantly, we observed that the expression of most identified structural and cell-adhesion genes was very low 
in our primary brown adipocyte cultures, despite having detectable expression in BAT itself. This might suggest that in vivo these genes are expressed in BAT by non-adipocyte cell types, such as endothelial cells and immune cells, and that these cell types play an essential role in maintaining an optimal microenvironment for BAT (Pope et al. 2016, Panina et al. 2018).

Upstream regulator analysis of the sex-differentially expressed genes identified ERBB2 and TGF $\beta 1$ as the most significant upstream regulators. ERBB2, a transmembrane tyrosine kinase receptor protein, is present in adiposederived stem cells and is involved in adipogenic proliferation and differentiation (Scioli et al. 2014). TGF $\beta 1$, a member of the TGF $\beta$ family of growth and differentiation factors, functions in adipose-derived stem cells to promote angiogenesis for optimal blood supply during adipose expansion (Scioli et al. 2014). In mice, serum TGF $\beta 1$ levels correlate with obesity and blocking of its principal signal transducer Smad3 or treatment with a TGF $\beta 1$ neutralizing antibody resulted in browning of WAT and prevented the development of obesity (Yadav et al. 2011). Upstream regulator analysis also identified E2, progesterone, and DHT as endogenous hormones regulating the expression of the identified genes. Our findings that ovariectomy reduced the mRNA expression levels while orchiectomy almost had no significant effect, strongly suggest a predominant role for female sex steroids in the sex-dimorphic expression pattern in BAT.

As discussed previously, most of the identified structural and cell-adhesion genes are likely expressed by non-adipocyte cell types in BAT. Additional studies, such as single-cell approaches that address the tissue cell heterogeneity, are therefore needed to determine which cell types express these genes in order to identify their role in BAT and whether these genes are directly regulated by sex steroids. Based on the literature, progesterone might regulate the expression of our identified genes, such as $C d h 1, C f d$, and Lcn2, because these have been reported to show progesterone-dependent regulation in the endometrium, a tissue that becomes highly vascularized during the preimplantation stage (Yao et al. 2003, Jeong et al. 2005, Jha et al. 2006, Liu et al. 2016).

The role of progesterone in regulating BAT function has been studied in much less detail than the other female sex steroid E2, despite its elevated levels during the luteal phase and pregnancy. Furthermore, available data for progesterone effects on BAT activity are conflicting. Regarding the thermogenic function of BAT, progesterone treatment was found to induce NE-stimulated Ucp1 mRNA expression in primary cultures of mouse brown adipocytes, but surprisingly only at the lowest concentration of $10^{-9} \mathrm{M}$ and not at higher concentrations of $10^{-8}$ or $10^{-7}$ M (Rodriguez et al. 2002). In contrast, another study showed that the mRNA expression of Ucp1 and other thermogenic genes in murine BAT was reduced during pregnancy as well as by in vivo progesterone treatment. Furthermore, treatment of primary brown adipocytes by $5 \times 10^{-7} \mathrm{M}$ progesterone reduced NE-stimulated Ucp1 mRNA expression (Mcllvride et al. 2017). In our study, progesterone stimulation of primary brown adipocytes at a physiological concentration for female mice $\left(10^{-7} \mathrm{M}\right)$ (Nilsson et al. 2015) or at supra-physiological concentrations $\left(10^{-6}\right.$ and $\left.10^{-5} \mathrm{M}\right)$ did not affect Ucp1 mRNA expression. However, in the T37i brown adipocytes, progesterone treatment at high concentrations $\left(10^{-5.5}\right.$ and $10^{-5} \mathrm{M}$ ) clearly inhibited Ucp1 mRNA expression. Expression of common mature brown adipocyte markers such as Ppargc1a, Pparg, and Fabp4 was not regulated by progesterone in primary cultures, although they showed a sex-dependent expression pattern, being higher in female than in male adipocytes. Of note, concentrations of progesterone used in our study should be adequate to mediate progesterone effects because its equilibrium dissociation constant $\left(K_{\mathrm{d}}\right)$ has been reported to be $2-3 \mathrm{nM}$ in various tissues (Jacobs \& Smith 1981).

The difference in progesterone effects in SVFdifferentiated brown adipocytes and T37i brown adipocytes might be driven by differences in the expression level of PR and its interaction with GR (Ruiz et al. 2020). In addition, the recently suggested functional heterogeneity of brown adipocytes and/or the presence of other cell types (e.g. macrophages, endothelial cells, fibroblasts) with adipocytes in the primary cultures could contribute to differences compared with a clonal cell (Bora \& Majumdar 2017, Song et al. 2020). Hence, further studies are required to investigate the in vivo effects of progesterone on the BAT transcriptional profile and function to draw firm conclusions about the role of progesterone in the regulation of BAT activity and to determine whether it plays a role in the observed sex differences in BAT and whether this is important in humans and might be an underlying factor in clinical conditions. A study in rats has shown that energy balance and energy intake varies during the estrous cycle (Giles et al. 2010). So far, these changes during the cycle have been thought to be driven by changes in circulating estrogens. However, based on our results we speculate that changes in circulating progesterone, leading to an altered estrogen/progesterone ratio, also play a role. Moreover, UCP1-independent regulation of BAT thermogenesis, such as creatine and 
lipid cycling, should not be ruled out (Chouchani et al. 2019), although the genes involved in these pathways were not identified in our in silico analysis.

Apart from its role in thermogenesis, BAT also serves as an endocrine organ, secreting several proteins including adiponectin and adipsin (also known as complement factor D) (Ali Khan etal.2018, Villarroya et al. 2019) of which the gene expressions in primary brown adipocytes were dosedependently reduced by progesterone. Adiponectin is a metabolic-favorable adipokine, having insulin-sensitizing and anti-inflammatory effects, of which the plasma concentrations are reduced in obesity (Stern et al. 2016, Achari \& Jain 2017). The fact that ovariectomy increased while pregnancy decreased plasma adiponectin levels suggests an inhibitory effect of progesterone (or other pregnancy-related hormones) on adiponectin secretion from adipocytes (Combs et al. 2003), which is in line with our in vitro results. However, another study in female rats found no significant effect of progesterone treatment on Adipoq mRNA expression in BAT but instead observed reduced Adipoq mRNA in inguinal WAT (Stelmanska et al. 2012). Adipsin is necessary for initiation of the alternative complement pathway, an innate immune response for pathogen recognition and elimination $(\mathrm{Xu}$ et al. 2001) and plays a role in maintaining pancreatic $\beta$ cell function (Lo et al. 2014). Adipsin also indirectly promotes adipogenesis and triglyceride storage in adipocytes via the product of its enzymatic action, the acylation-stimulating protein (ASP) (Cianflone et al. 2003, Song et al. 2016). Our results show that progesterone inhibited adipsin expression in primary brown adipocytes of murine origin. It remains to be determined how these results translate to human since serum adipsin levels were reduced during pregnancy but did not differ between the follicular and luteal phase in humans (Poveda et al. 2016).

Interestingly, using different concentrations of RU486 revealed that the progesterone-inhibiting effects on mRNA expression of various genes in brown adipocytes are possibly driven by GR rather than PR because the inhibition was blunted when RU486 was applied at a GR- and PR-antagonistic concentration but not at a more PR-specific antagonistic concentration (Kroon et al. 2018). Our findings agree with previous studies, for instance, progesterone was reported to act via the GR to mediate regulatory $\mathrm{T}$ cell enrichment (Engler et al. 2017) and to repress PTGS2 mRNA expression in myometrial cells (Lei et al. 2012). However, non-genomic actions of progesterone, for example, through progesterone membrane receptors and the progesterone receptor membrane components, cannot be ruled out.
In summary, this study demonstrates a sex-dependent transcriptomic profile in BAT of mice at basal conditions and suggests a role for progesterone in the regulation of some of the identified sex-differentially expressed genes. Furthermore, our results highlight a role for genes encoding proteins involved in cellular structure, cell-cell contact, and cell adhesion in the sex-differential function of BAT.

\section{Supplementary materials}

This is linked to the online version of the paper at https://doi.org/10.1530/ JME-20-0210.

\section{Declaration of interest}

The authors declare that there is no conflict of interest that could be perceived as prejudicing the impartiality of the research reported.

\section{Funding}

This research did not receive any specific grant from any funding agency in the public, commercial or not-for-profit sector.

\section{Author contribution statement}

K K, A G and J A V conceived study. K K, A G, J S and A M designed and performed experiments. S M A S was involved in RNA-seq data analysis. KK, $A G$ and $J S$ were involved in all other data analyses. All authors contributed to result interpretation. $\mathrm{K} \mathrm{K}, \mathrm{A} G$ and $\mathrm{J} A \mathrm{~V}$ involved in manuscript preparation. All authors reviewed and approved the manuscript.

\section{Acknowledgement}

The authors would like to thank Chen Hu for her valuable assistance during the experiment.

\section{References}

Achari AE \& Jain SK 2017 Adiponectin, a therapeutic target for obesity, diabetes, and endothelial dysfunction. International Journal of Molecular Sciences 18 E1321. (https://doi.org/10.3390/ijms18061321)

Ali Khan A, Hansson J, Weber P, Foehr S, Krijgsveld J, Herzig S \& Scheideler M 2018 Comparative secretome analyses of primary murine white and brown adipocytes reveal novel adipokines. Molecular and Cellular Proteomics 17 2358-2370. (https://doi. org/10.1074/mcp.RA118.000704)

Basu S, Cheriyamundath S \& Ben-Ze'ev A 2018 Cell-cell adhesion: linking Wnt/beta-catenin signaling with partial EMT and stemness traits in tumorigenesis. F1000Research 7 7. (https://doi.org/10.12688/ f1000research.15782.1)

Bora P \& Majumdar AS 2017 Adipose tissue-derived stromal vascular fraction in regenerative medicine: a brief review on biology and translation. Stem Cell Research and Therapy 8 145. (https://doi. org/10.1186/s13287-017-0598-y)

Cannon B \& Nedergaard J 2004 Brown adipose tissue: function and physiological significance. Physiological Reviews 84 277-359. (https:// doi.org/10.1152/physrev.00015.2003) 
Choe SS, Huh JY, Hwang IJ, Kim JI \& Kim JB 2016 Adipose tissue remodeling: its role in energy metabolism and metabolic disorders. Frontiers in Endocrinology 7 30. (https://doi.org/10.3389/ fendo.2016.00030)

Chouchani ET, Kazak L \& Spiegelman BM 2019 New advances in adaptive thermogenesis: UCP1 and beyond. Cell Metabolism 29 27-37. (https://doi.org/10.1016/j.cmet.2018.11.002)

Cianflone K, Xia Z \& Chen LY 2003 Critical review of acylationstimulating protein physiology in humans and rodents. Biochimica et Biophysica Acta 1609 127-143. (https://doi.org/10.1016/s00052736(02)00686-7)

Combs TP, Berg AH, Rajala MW, Klebanov S, Iyengar P, JimenezChillaron JC, Patti ME, Klein SL, Weinstein RS \& Scherer PE 2003 Sexual differentiation, pregnancy, calorie restriction, and aging affect the adipocyte-specific secretory protein adiponectin. Diabetes $\mathbf{5 2}$ 268-276. (https://doi.org/10.2337/diabetes.52.2.268)

Cypess AM, Lehman S, Williams G, Tal I, Rodman D, Goldfine AB, Kuo FC, Palmer EL, Tseng YH, Doria A, et al. 2009 Identification and importance of brown adipose tissue in adult humans. New England Journal of Medicine 360 1509-1517. (https://doi.org/10.1056/ NEJMoa0810780)

Dobin A, Davis CA, Schlesinger F, Drenkow J, Zaleski C, Jha S, Batut P, Chaisson M \& Gingeras TR 2013 STAR: ultrafast universal RNA-seq aligner. Bioinformatics 29 15-21. (https://doi.org/10.1093/ bioinformatics/bts635)

Engler JB, Kursawe N, Solano ME, Patas K, Wehrmann S, Heckmann N, Luhder F, Reichardt HM, Arck PC, Gold SM, et al. 2017 Glucocorticoid receptor in T cells mediates protection from autoimmunity in pregnancy. PNAS 114 E181-E190. (https://doi. org/10.1073/pnas.1617115114)

Feldmann HM, Golozoubova V, Cannon B \& Nedergaard J 2009 UCP1 ablation induces obesity and abolishes diet-induced thermogenesis in mice exempt from thermal stress by living at thermoneutrality. Cell Metabolism 9 203-209. (https://doi.org/10.1016/j. cmet.2008.12.014)

GBD 2015 Obesity Collaborators, Afshin A, Forouzanfar MH, Reitsma MB, Sur P, Estep K, Lee A, Marczak L, Mokdad AH, MoradiLakeh M, et al. 2017 Health effects of overweight and obesity in 195 countries over 25 years. New England Journal of Medicine 377 13-27. (https://doi.org/10.1056/NEJMoa1614362)

Geer EB \& Shen W 2009 Gender differences in insulin resistance, body composition, and energy balance. Gender Medicine 6 (Supplement 1) 60-75. (https://doi.org/10.1016/j. genm.2009.02.002)

Giles ED, Jackman MR, Johnson GC, Schedin PJ, Houser JL \& MacLean PS 2010 Effect of the estrous cycle and surgical ovariectomy on energy balance, fuel utilization, and physical activity in lean and obese female rats. American Journal of Physiology: Regulatory, Integrative and Comparative Physiology 299 R1634-R1642. (https://doi.org/10.1152/ajpregu.00219.2010)

Gonzalez-Garcia I, Tena-Sempere M \& Lopez M 2017 Estradiol regulation of brown adipose tissue thermogenesis. Advances in Experimental Medicine and Biology 1043 315-335. (https://doi.org/10.1007/978-3319-70178-3_15)

Grefhorst A, van den Beukel JC, van Houten EL, Steenbergen J, Visser JA \& Themmen AP 2015 Estrogens increase expression of bone morphogenetic protein $8 \mathrm{~b}$ in brown adipose tissue of mice. Biology of Sex Differences 6 7. (https://doi.org/10.1186/s13293-015-0025-y)

Gumbiner BM 1996 Cell adhesion: the molecular basis of tissue architecture and morphogenesis. Cell 84 345-357. (https://doi. org/10.1016/s0092-8674(00)81279-9)

Hashimoto O, Noda T, Morita A, Morita M, Ohtsuki H, Sugiyama M \& Funaba M 2016 Castration induced browning in subcutaneous white adipose tissue in male mice. Biochemical and Biophysical Research Communications 478 1746-1750. (https://doi.org/10.1016/j. bbrc.2016.09.017)
Huang da W, Sherman BT \& Lempicki RA 2009 Systematic and integrative analysis of large gene lists using DAVID bioinformatics resources. Nature Protocols 4 44-57. (https://doi.org/10.1038/ nprot.2008.211)

Jacobs BR \& Smith RG 1981 A comparison of progesterone and R5020 binding in endometrium, ovary, pituitary, and hypothalamus. Fertility and Sterility 35 438-441. (https://doi.org/10.1016/S00150282(16)45440-3)

Jeong JW, Lee KY, Kwak I, White LD, Hilsenbeck SG, Lydon JP \& DeMayo FJ 2005 Identification of murine uterine genes regulated in a ligand-dependent manner by the progesterone receptor. Endocrinology 146 3490-3505. (https://doi.org/10.1210/en.20050016)

Jha RK, Titus S, Saxena D, Kumar PG \& Laloraya M 2006 Profiling of E-cadherin, beta-catenin and $\mathrm{Ca}(2+)$ in embryo-uterine interactions at implantation. FEBS Letters 580 5653-5660. (https://doi. org/10.1016/j.febslet.2006.09.014)

Joo JI \& Yun JW 2011 Gene expression profiling of adipose tissues in obesity susceptible and resistant rats under a high fat diet. Cellular Physiology and Biochemistry 27 327-340. (https://doi. org/10.1159/000327959)

Kaikaew K, Steenbergen J, Themmen APN, Visser JA \& Grefhorst A 2017 Sex difference in thermal preference of adult mice does not depend on presence of the gonads. Biology of Sex Differences 8 24. (https:// doi.org/10.1186/s13293-017-0145-7)

Kaikaew K, Steenbergen J, van Dijk TH, Grefhorst A \& Visser JA 2019 Sex difference in corticosterone-induced insulin resistance in mice. Endocrinology 160 2367-2387. (https://doi.org/10.1210/en.201900194)

Kramer A, Green J, Pollard Jr J \& Tugendreich S 2014 Causal analysis approaches in ingenuity pathway analysis. Bioinformatics $\mathbf{3 0}$ 523-530. (https://doi.org/10.1093/bioinformatics/btt703)

Kroon J, Koorneef LL, van den Heuvel JK, Verzijl CRC, van de Velde NM, Mol IM, Sips HCM, Hunt H, Rensen PCN \& Meijer OC 2018 Selective glucocorticoid receptor antagonist CORT125281 activates brown adipose tissue and alters lipid distribution in male mice. Endocrinology 159 535-546. (https://doi.org/10.1210/ en.2017-00512)

Lei K, Chen L, Georgiou EX, Sooranna SR, Khanjani S, Brosens JJ, Bennett PR \& Johnson MR 2012 Progesterone acts via the nuclear glucocorticoid receptor to suppress IL-1beta-induced COX-2 expression in human term myometrial cells. PLoS ONE 7 e50167. (https://doi.org/10.1371/journal.pone.0050167)

Liao Y, Smyth GK \& Shi W 2014 featureCounts: an efficient general purpose program for assigning sequence reads to genomic features. Bioinformatics 30 923-930. (https://doi.org/10.1093/bioinformatics/ btt656)

Liu X, Zheng Z, Zhu X, Meng M, Li L, Shen Y, Chi Q, Wang D, Zhang Z, Li C, et al. 2013 Brown adipose tissue transplantation improves whole-body energy metabolism. Cell Research 23 851-854. (https:// doi.org/10.1038/cr.2013.64)

Liu YF, Deng WB, Li SY, Yao MN, Liu J, Dou HT, Zhao ML, Yang ZM \& Liang XH 2016 Progesterone induces the expression of lipocalin-2 through Akt-c-Myc pathway during mouse decidualization. FEBS Letters 590 2594-2602. (https://doi. org/10.1002/1873-3468.12304)

Lo JC, Ljubicic S, Leibiger B, Kern M, Leibiger IB, Moede T, Kelly ME, Chatterjee Bhowmick D, Murano I, Cohen P, et al. 2014 Adipsin is an adipokine that improves beta cell function in diabetes. Cell 158 41-53. (https://doi.org/10.1016/j. cell.2014.06.005)

Logue J, Walker JJ, Colhoun HM, Leese GP, Lindsay RS, McKnight JA, Morris AD, Pearson DW, Petrie JR, Philip S, et al. 2011 Do men develop type 2 diabetes at lower body mass indices than women? Diabetologia 54 3003-3006. (https://doi.org/10.1007/s00125-0112313-3) 
Longo M, Zatterale F, Naderi J, Parrillo L, Formisano P, Raciti GA, Beguinot F \& Miele C 2019 Adipose tissue dysfunction as determinant of obesity-associated metabolic complications. International Journal of Molecular Sciences 20 2358. (https://doi. org/10.3390/ijms20092358)

Love MI, Huber W \& Anders S 2014 Moderated estimation of fold change and dispersion for RNA-seq data with DESeq2. Genome Biology 15 550. (https://doi.org/10.1186/s13059-014-0550-8)

Martin M 2011 Cutadapt removes adapter sequences from highthroughput sequencing reads. EMBnet.Journal 17 10-12. (https://doi. org/10.14806/ej.17.1.200)

Martinez de Morentin PB, Gonzalez-Garcia I, Martins L, Lage R, Fernandez-Mallo D, Martinez-Sanchez N, Ruiz-Pino F, Liu J, Morgan DA, Pinilla L, et al. 2014 Estradiol regulates brown adipose tissue thermogenesis via hypothalamic AMPK. Cell Metabolism 20 41-53. (https://doi.org/10.1016/j.cmet.2014.03.031)

Maurer SF, Fromme T, Mocek S, Zimmermann A \& Klingenspor M 2020 Uncoupling protein 1 and the capacity for nonshivering thermogenesis are components of the glucose homeostatic system. American Journal of Physiology: Endocrinology and Metabolism $\mathbf{3 1 8}$ E198-E215. (https://doi.org/10.1152/ajpendo.00121.2019)

Mauvais-Jarvis F 2015 Sex differences in metabolic homeostasis, diabetes, and obesity. Biology of Sex Differences 6 14. (https://doi. org/10.1186/s13293-015-0033-y)

Mauvais-Jarvis F, Clegg DJ \& Hevener AL 2013 The role of estrogens in control of energy balance and glucose homeostasis. Endocrine Reviews 34 309-338. (https://doi.org/10.1210/er.2012-1055)

McIlvride S, Mushtaq A, Papacleovoulou G, Hurling C, Steel J, Jansen E, Abu-Hayyeh S \& Williamson C 2017 A progesterone-brown fat axis is involved in regulating fetal growth. Scientific Reports 710671. (https://doi.org/10.1038/s41598-017-10979-7)

Monjo M, Rodriguez AM, Palou A \& Roca P 2003 Direct effects of testosterone, 17 beta-estradiol, and progesterone on adrenergic regulation in cultured brown adipocytes: potential mechanism for gender-dependent thermogenesis. Endocrinology 144 4923-4930. (https://doi.org/10.1210/en.2003-0537)

Moonen MPB, Nascimento EBM \& van Marken Lichtenbelt WD 2019 Human brown adipose tissue: underestimated target in metabolic disease? Biochimica et Biophysica Acta: Molecular and Cell Biology of Lipids 1864 104-112. (https://doi.org/10.1016/j. bbalip.2018.05.012)

Newell-Fugate AE 2017 The role of sex steroids in white adipose tissue adipocyte function. Reproduction 153 R133-R149. (https://doi. org/10.1530/REP-16-0417)

Nilsson ME, Vandenput L, Tivesten Å, Norlen AK, Lagerquist MK, Windahl SH, Borjesson AE, Farman HH, Poutanen M, Benrick A, et al. 2015 Measurement of a comprehensive sex steroid profile in rodent serum by high-sensitive gas chromatography-tandem mass spectrometry. Endocrinology 156 2492-2502. (https://doi.org/10.1210/ en.2014-1890)

Palmer BF \& Clegg DJ 2015 The sexual dimorphism of obesity. Molecular and Cellular Endocrinology 402 113-119. (https://doi.org/10.1016/j. mce.2014.11.029)

Panina YA, Yakimov AS, Komleva YK, Morgun AV, Lopatina OL, Malinovskaya NA, Shuvaev AN, Salmin VV, Taranushenko TE \& Salmina AB 2018 Plasticity of adipose tissue-derived stem cells and regulation of angiogenesis. Frontiers in Physiology 9 1656. (https://doi. org/10.3389/fphys.2018.01656)

Perez-Perez R, Ortega-Delgado FJ, Garcia-Santos E, Lopez JA, Camafeita E, Ricart W, Fernandez-Real JM \& Peral B 2009 Differential proteomics of omental and subcutaneous adipose tissue reflects their unalike biochemical and metabolic properties. Journal of Proteome Research $\mathbf{8}$ 1682-1693. (https://doi.org/10.1021/pr800942k)

Pope BD, Warren CR, Parker KK \& Cowan CA 2016 Microenvironmental control of adipocyte fate and function. Trends in Cell Biology 26 745-755. (https://doi.org/10.1016/j.tcb.2016.05.005)
Poveda NE, Garces MF, Ruiz-Linares CE, Varon D, Valderrama S, Sanchez E, Castiblanco-Cortes A, Agudelo-Zapata Y, SandovalAlzate HF, Leal LG, et al. 2016 Serum adipsin levels throughout normal pregnancy and preeclampsia. Scientific Reports 620073. (https://doi.org/10.1038/srep20073)

Rodriguez AM, Monjo M, Roca P \& Palou A 2002 Opposite actions of testosterone and progesterone on UCP1 mRNA expression in cultured brown adipocytes. Cellular and Molecular Life Sciences 59 1714-1723. (https://doi.org/10.1007/pl00012499)

Rodriguez-Cuenca S, Pujol E, Justo R, Frontera M, Oliver J, Gianotti M \& Roca P 2002 Sex-dependent thermogenesis, differences in mitochondrial morphology and function, and adrenergic response in brown adipose tissue. Journal of Biological Chemistry 277 42958-42963. (https://doi.org/10.1074/jbc.M207229200)

Rogers NH, Perfield 2nd JW, Strissel KJ, Obin MS \& Greenberg AS 2009 Reduced energy expenditure and increased inflammation are early events in the development of ovariectomy-induced obesity. Endocrinology 150 2161-2168. (https://doi.org/10.1210/ en.2008-1405)

Rudnicki M, Abdifarkosh G, Rezvan O, Nwadozi E, Roudier E \& Haas TL 2018 Female mice have higher angiogenesis in perigonadal adipose tissue than males in response to high-fat diet. Frontiers in Physiology 9 1452. (https://doi.org/10.3389/fphys.2018.01452)

Ruiz D, Padmanabhan V \& Sargis RM 2020 Stress, sex, and sugar: glucocorticoids and sex-steroid crosstalk in the sex-specific misprogramming of metabolism. Journal of the Endocrine Society $\mathbf{4}$ bvaa087. (https://doi.org/10.1210/jendso/bvaa087)

Scioli MG, Bielli A, Gentile P, Mazzaglia D, Cervelli V \& Orlandi A 2014 The biomolecular basis of adipogenic differentiation of adiposederived stem cells. International Journal of Molecular Sciences $\mathbf{1 5}$ 6517-6526. (https://doi.org/10.3390/ijms15046517)

Song NJ, Kim S, Jang BH, Chang SH, Yun UJ, Park KM, Waki H, Li DY, Tontonoz P \& Park KW 2016 Small molecule-induced complement factor D (adipsin) promotes lipid accumulation and adipocyte differentiation. PLOS ONE 11 e0162228. (https://doi.org/10.1371/ journal.pone.0162228)

Song A, Dai W, Jang MJ, Medrano L, Li Z, Zhao H, Shao M, Tan J, Li A, Ning T, et al. 2020 Low- and high-thermogenic brown adipocyte subpopulations coexist in murine adipose tissue. Journal of Clinical Investigation 130 247-257. (https://doi.org/10.1172/ JCI129167)

Stelmanska E, Kmiec Z \& Swierczynski J 2012 The gender- and fat depotspecific regulation of leptin, resistin and adiponectin genes expression by progesterone in rat. Journal of Steroid Biochemistry and Molecular Biology 132 160-167. (https://doi.org/10.1016/j. jsbmb.2012.05.005)

Stern JH, Rutkowski JM \& Scherer PE 2016 Adiponectin, leptin, and fatty acids in the maintenance of metabolic homeostasis through adipose tissue crosstalk. Cell Metabolism 23 770-784. (https://doi. org/10.1016/j.cmet.2016.04.011)

Townsend K \& Tseng YH 2012 Brown adipose tissue: recent insights into development, metabolic function and therapeutic potential. Adipocyte 1 13-24. (https://doi.org/10.4161/adip.18951)

Villarroya J, Cereijo R, Gavalda-Navarro A, Peyrou M, Giralt M \& Villarroya F 2019 New insights into the secretory functions of brown adipose tissue. Journal of Endocrinology 243 R19-R27. (https://doi. org/10.1530/JOE-19-0295)

Xu Y, Ma M, Ippolito GC, Schroeder Jr HW, Carroll MC \& Volanakis JE 2001 Complement activation in factor D-deficient mice. PNAS 98 14577-14582. (https://doi.org/10.1073/ pnas.261428398)

Yadav H, Quijano C, Kamaraju AK, Gavrilova O, Malek R, Chen W, Zerfas P, Zhigang D, Wright EC, Stuelten C, et al. 2011 Protection from obesity and diabetes by blockade of TGF-beta/Smad3 signaling. Cell Metabolism 14 67-79. (https://doi.org/10.1016/j. cmet.2011.04.013) 
Yao MW, Lim H, Schust DJ, Choe SE, Farago A, Ding Y, Michaud S, Church GM \& Maas RL 2003 Gene expression profiling reveals progesterone-mediated cell cycle and immunoregulatory roles of Hoxa-10 in the preimplantation uterus. Molecular Endocrinology 17 610-627. (https://doi.org/10.1210/me.2002-0290)

Yoshioka K, Yoshida T, Wakabayashi Y, Nishioka H \& Kondo M 1988 Reduced brown adipose tissue thermogenesis of obese rats after ovariectomy. Endocrinologia Japonica 35 537-543. (https://doi. org/10.1507/endocrj1954.35.537)

Zennaro MC, Le Menuet D, Viengchareun S, Walker F, Ricquier D \& Lombes M 1998 Hibernoma development in transgenic mice identifies brown adipose tissue as a novel target of aldosterone action. Journal of Clinical Investigation 101 1254-1260. (https://doi. org/10.1172/JCI1915)

Received in final form 5 November 2020

Accepted 20 November 2020

Accepted Manuscript published online 25 November 2020
(C) 2021 Society for Endocrinology Published by Bioscientifica Ltd. Printed in Great Britain 